Document downloaded from:

http://hdl.handle.net/10251/111245

This paper must be cited as:

Muñoz Mas, R.; Marcos-García, P.; Lopez-Nicolas, A.; Martínez-García, F.; PulidoVelazquez, M.; Martinez-Capel, F. (2018). Combining literature-based and data-driven fuzzy models to predict brown trout (salmo trutta I.) spawning habitat degradation induced by climate change. Ecological Modelling. 386:98-114. doi:10.1016/j.ecolmodel.2018.08.012

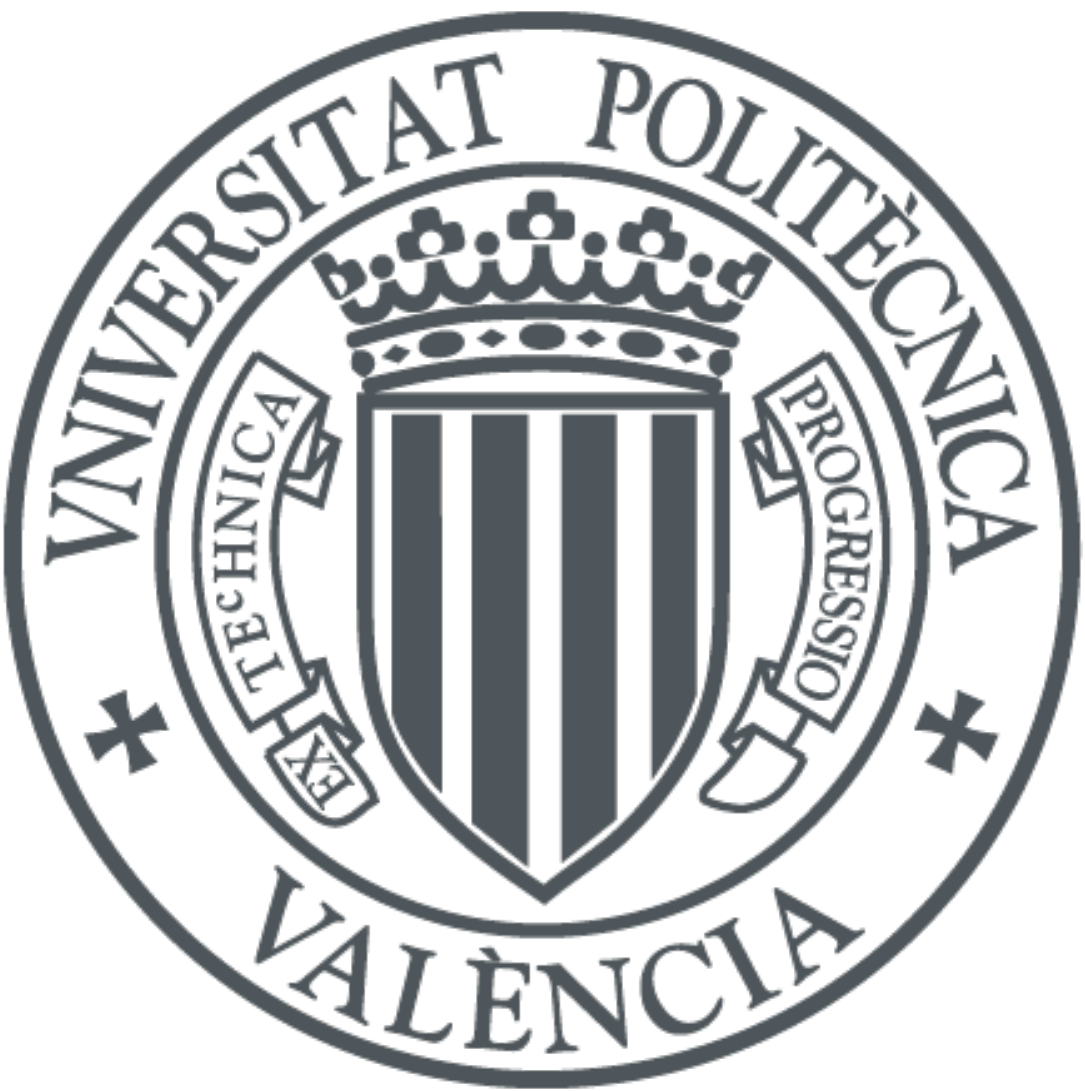

The final publication is available at

https://doi.org/10.1016/j.ecolmodel.2018.08.012

Copyright Elsevier

Additional Information 


\section{COMBINING LITERATURE-BASED AND DATA-DRIVEN FUZZY MODELS TO PREDICT BROWN TROUT (Salmo trutta L.) SPAWNING HABITAT DEGRADATION INDUCED BY CLIMATE CHANGE}

Rafael Muñoz-Mas ${ }^{1}$, Patricia Marcos-Garcia², Antonio Lopez-Nicolas², Francisco J. Martínez-García ${ }^{3}$, Manuel Pulido-Velazquez² ${ }^{\text {Francisco Martínez-Capel }}{ }^{1}$

${ }^{1}$ Institut d'Investigació per a la Gestió Integrada de Zones Costaneres (IGIC), Universitat Politècnica de València, Paranimf 1, 46730 Grau de Gandia (València), País Valencià, Spain.

${ }^{2}$ Research Institute of Water and Environmental Engineeering (IIAMA), Universitat Politècnica de València, Camí de Vera s/n, 46022 Valencia, Spain

${ }^{3}$ Servicio de Caza y Pesca, Generalitat Valenciana, Castán Tobeñas 77 (Ciudad Administrativa 9 de octubre - Torre 1), 46018 Valencia, Spain.

\section{Keywords}

Differential Evolution

HBV-light

M5

Multi-Adaptive Regression Splines

Support Vector Regression

Takagi-Sugeno-Kang fuzzy rule-based system 


\section{Abstract}

A fuzzy rule-based system combining empirical data on hydraulic preferences and literature information on temperature requirements was used to foresee the brown trout (Salmo trutta L.) spawning habitat degradation induced by climate change. The climatic scenarios for the Cabriel River (Eastern Iberian Peninsula) corresponded to two Representative Concentration Pathways (4.5 and 8.5) for the short (2011-2040) and mid (2041-2070) term horizons. The hydraulic and hydrologic modelling were undertaken with process-based numerical models (i.e., River2 $\mathrm{D}^{\odot}$ and HBV-light) while the water temperature was modelled by assembling the predictions of three machine learning techniques (M5, Multi-Adaptive Regression Splines and Support Vector Regression). The predicted rise in the water temperature will not be compensated by the more benign lower flows. Consequently, the suitable spawning habitat will be reduced between $15.4-48.7 \%$. The entire population shall suffer the effects of climate change and will probably be extirpated from the downstream segments of the river.

\section{LIST OF ACRONYMS}

CV - Cross-Validation

DE - Differential Evolution

GAM - Generalised Additive Model

HDC - Habitat Duration Curve

MARS - Multi-Adaptive Regression Splines 
NSE - Nash-Sutcliffe Efficiency

$Q$ - Flow rate

RCP - Representative Concentration Pathway

SA - Suitable Area

Sn - Sensitivity

Sp - Specificity

SVR - Support Vector Regression

TSK - Takagi-Sugeno-Kang fuzzy rule-based system

TSS - True Skill Statistic

wMSE - weighted Mean Squared Error

WSE - Water Surface Elevation

WUA - Weighted Usable Area

\section{Introduction}

Despite the increasing number of notorious climate change deniers in the current post-truth era (Ratuva, 2017), where scientific evidence is systematically questioned (Rabin-Havt, 2016), 2016 was the third consecutive year to set a new global annual temperature record (NASA, 2017). Freshwater fish species are not immune to the effects of global warming (Comte et al., 2013). Accordingly, coinciding with a corroborated warming trend, the range shifts of freshwater fish have, over the centuries, been an ongoing phenomenon (Clavero et al., 2017). However, although global warming may impact other fish families similar to the 
Salmonidae family (e.g., Sánchez-Hernández and Nunn, 2016), it has been assumed that global warming may benefit warm-water species (Comte et al., 2013). In accordance, studies about salmonids prevail over any other family (Comte et al., 2013), due to their crucial role within cold-water food webs and the number of ecosystem services they provide (Kovach et al., 2016).

One paradigmatic salmonid is the brown trout (Salmo trutta L., 1758), which has been successfully introduced across the globe due to its ecological tolerance and its reputation as fine food and good sport (Klemetsen et al., 2003). Brown trout is a well-known indicator species because it is strictly a cold-water species and thus, sensitive to rising temperatures (Clavero et al., 2017; Tisseuil et al., 2012). In accordance, significant shifts in the brown trout distribution range are expected as global temperatures increase over the century (Santiago, 2017; Comte et al., 2013; Lassalle and Rochard, 2009).

Contemporary studies (e.g., Santiago et al., 2017; Muñoz-Mas et al., 2016b) are typically only based on adults, neglecting the environmental requirements of life-history stages such as embryos or larvae (Réalis-Doyelle et al., 2016; Louhi et al., 2008). However, rising temperatures, and peak events, may have asymmetrical effects depending on the development life stage (Santiago, 2017), with later developmental stages (e.g., adults) depicting lower temperature sensitivity than earlier stages (Lahnsteiner, 2012; Elliott and Elliott, 2010). The thermotolerance of brown trout has been studied and reported over the centuries to satisfy aquaculture needs (Réalis-Doyelle et al., 2016; Ojanguren and Braña, 2003; Embody, 1934; Norris, 1868), which supplies a vast amount of data - hardly obtainable in natural streams - that can be used to develop temperature suitability models (Noack et al., 2017). In accordance with these studies, in some Mediterranean climates, global warming is likely to affect the sessile stages (e.g., embryos) to a greater extent because they present a narrower thermal tolerance (Elliott and Elliott, 2010), while mobile 
individuals may be, on one hand, able to tolerate a larger range of water temperature and, on the other hand, may potentially be able to find available thermal refugia (Elliott and Elliott, 2010; Elliott, 2000). Brown trout spawning, and subsequent recruitment (i.e., the number of fish surviving to enter the fishery), can govern population density and production (Lobón-Cerviá, 2009), which highlights the importance of studying the future climateinduced degradation of the spawning habitat to foresee future population dynamics.

Successful trout incubation requires suitable temperatures, favoured by egg burial (Hansen, 1975), with deviations compromising embryo survival (Wes Stonecypher et al., 1994). Lower temperatures prolong incubation, which favour pathogen outbreaks (Meyer, 1991; Barker et al., 1989), while higher temperature tend to increase the ratio of malformations (Réalis-Doyelle et al., 2016), despite accelerating trout hatching (Ojanguren and Braña, 2003; Jungwirth and Winkler, 1984; Embody, 1934).

Increased stream temperatures are one of the primary - but not the sole - potential outcomes of rapid global warming (Hauer et al., 2013) because such a phenomenon is embedded within the alteration of the precipitation patterns (i.e., climate change), which is leading to modified flow regimes (Van Vliet et al., 2013). Freshwater organisms have evolved and adapted specifically to the natural flow regime (Poff et al., 1997; Townsend and Hildrew, 1994) and thus, changes in the frequency of magnitude, timing and duration of the different flows may lead to remarkable changes or to ecosystem collapses (Perkins et al., 2010). Therefore, while some regions in the world expect increases in water yield (Van Vliet et al., 2013), others, such as the Eastern Mediterranean region of the Iberian Peninsula (Marcos-Garcia and Pulido-Velazquez, 2017; Salmoral et al., 2015; Chirivella Osma et al., 2014), are likely to be characterised by a continued decrease in water yield, which may result in a population bottleneck for species survival (e.g., Muñoz-Mas et al., 2016b). 
The most basic analytical approach successfully related temperature with future species distribution (e.g., Santiago et al., 2015; Isaak and Rieman, 2013), although river flow may also impact species distribution (Hauer et al., 2013; Wenger et al., 2011). This methodological framework enjoys popularity because water temperature can be easily predicted, with considerable accuracy, based on air temperature (Santiago et al., 2017; Piccolroaz et al., 2016). This task can also be addressed either by using flexible statistical models (Laanaya et al., 2017), such as Generalised Additive Models (GAMs) (Hastie and Tibshirani, 1990), or by employing machine learning techniques (e.g., Muñoz-Mas et al., 2016b); for instance, M5 model trees (Quinlan, 1992).

Certainly, these temperature-based approaches allow the evaluation of large areas, for instance, by employing stream isotherms (Isaak and Rieman, 2013). However, even though they usually account for the future flow regime (e.g., Santiago et al., 2017; SánchezHernández and Nunn, 2016; Tisseuil et al., 2012), the confounding influence of channel morphology should discourage the sole use of the flow regime, and related statistics, as proxies of changes in hydraulic conditions (i.e., flow velocity and water depth) (Turner and Stewardson, 2014). In accordance, studies applying frameworks accounting for a broader number of elements (e.g., temperature, flow and hydraulics), such as the physical habitat simulation approach (Bovee et al., 1998) - which combines habitat suitability modelling, hydraulic and hydrologic modelling and water temperature modelling - should be better suited to forecast the cumulative climate change-induced impacts on the target taxa. Interestingly, several studies applying the aforementioned framework observed how increases in the duration of low flows lead to augmentations in the overall habitat suitability of a given river section caused by the particular channel geometry (e.g., Li et al., 2015); thus, preconceiving the negative impact of decreased water yield for a specific taxa could be erroneous (see e.g., Muñoz-Mas et al., 2016d; Viganò et al., 2015). 
Sampling the hydraulic preferences for brown trout spawning and incubation in natural streams is feasible compared to reproducing them in the laboratory (e.g., Gauthey et al., 2015; Radtke, 2013), which should provide the necessary data to develop data-driven habitat suitability models (Noack et al., 2017). The habitat requirements proved to be especially relevant with regard to substrate composition because adequate substrate impedes egg scouring and favours stable redd temperature and satisfactory oxygenation (Noack et al., 2017; Gauthey et al., 2015; Hansen, 1975). Therefore, the optimal substrate granulometry typically ranges between 16-64 mm, which can be classified as gravel (sensu Muñoz-Mas et al., 2012), whereas the optimal depth and velocity range, respectively, between $0.15-0.45 \mathrm{~m}$ and $0.20-0.55 \mathrm{~m} / \mathrm{s}$ (Louhi et al., 2008).

In accordance with these hydraulic preferences, exclusively studying the changes in water temperature due to climate change may lead to incomplete assessments. Nonetheless, recent experiences in the Mediterranean region of the Iberian Peninsula indicated relevant changes for both water temperature and flow regime (Santiago et al., 2017), which will result in changes in the habitat suitability for the different life stages of trout (Muñoz-Mas et al., 2016b; Ayllón et al., 2013). Consequently, the increasing synchrony of high temperature and low flow will potentially lead to synergistic effects with dramatic consequences (Arismendi et al., 2013), which may be especially relevant at the rear edge of their original distribution range (i.e., the altitudinal and latitudinal margins of the natural distribution area) (Hampe and Petit, 2005).

Therefore, the present study aimed at predicting the brown trout spawning habitat degradation induced by climate change in a segment of the Cabriel River (Eastern Iberian Peninsula), which is located at the rear edge of the current brown trout distribution area. To achieve this aim, the study applied a framework based on the physical habitat simulation approach combining habitat suitability modelling, hydraulic and hydrologic modelling and 
water temperature modelling, which were fed with downscaled climatic data from the most recent climate change scenarios; the Representative Concentration Pathways (RCPs) 4.5

and 8.5. In accordance, i) a zero-order presence-absence Takagi-Sugeno-Kang fuzzy rulebased system combining a literature-based (water temperature) and a data-driven (hydraulics) module was developed to model the habitat suitability for brown trout spawning. The hydraulic modelling was ii) undertaken with River2 ${ }^{\odot}{ }^{\circ}$, while the hydrologic modelling was iii) performed with HBV-light (Seibert and Vis, 2012). The water temperature modelling was iv) modelled assembling the predictions of three machine learning techniques (M5, Multi-Adaptive Regression Splines and Support Vector Regression). Given the bivariate nature of the analysis (i.e., temperature and flow), the habitat-flow relationship was v) characterised with surfaces, instead of curves, and the simulated flows were vi) transduced to Habitat Time Series (HTSs). Finally, vii) the brown trout spawning habitat degradation was evaluated by comparing the frequency and magnitude of the extreme events (i.e., temperature and low flows peaks) through Habitat Duration Curves (HDCs).

\section{Methods}

\subsection{Study area}

The Cabriel River is the main tributary of the Júcar River and is $220 \mathrm{~km}$ in length, with 4,754 $\mathrm{km}^{2}$ of drainage area and $10.8 \mathrm{~m}^{3} / \mathrm{s}$ of mean flow (Vezza et al., 2015). The upstream part of the river is currently free-flowing while the downstream half was regulated in 1972 by means of a complex of storage and hydropower facilities; the most noticeable being the Contreras Dam (Muñoz-Mas et al., 2016e). The study site is located in a river segment immediately upstream of the first small reservoir regulating the basin (i.e., the Bujioso 
Reservoir) and is dominated by two cyprinid species, the Eastern Iberian barbel (Luciobarbus guiraonis Steindachner, 1866) and the Eastern Iberian Chub (Squalius valentinus Doadrio and Carmona, 2006) (Muñoz-Mas et al., 2016a, 2016e; Vezza et al., 2015), which indicates that the study site is located at the rear edge of the natural distribution area of the brown trout (Fig. 1) (Santos et al., 2004). The land cover of the upper part of the basin mainly consists of forested areas (86\%) and crops (12\%) (Bossard et al., 2000) and is affected by a steady depopulation trend, which is likely to continue until 2050 (INE, 2012). Therefore, we considered the effect of additional anthropogenic stressors to be negligible aside from global change (i.e., climatic and direct anthropogenic changes) (see e.g., Meybeck, 2004).

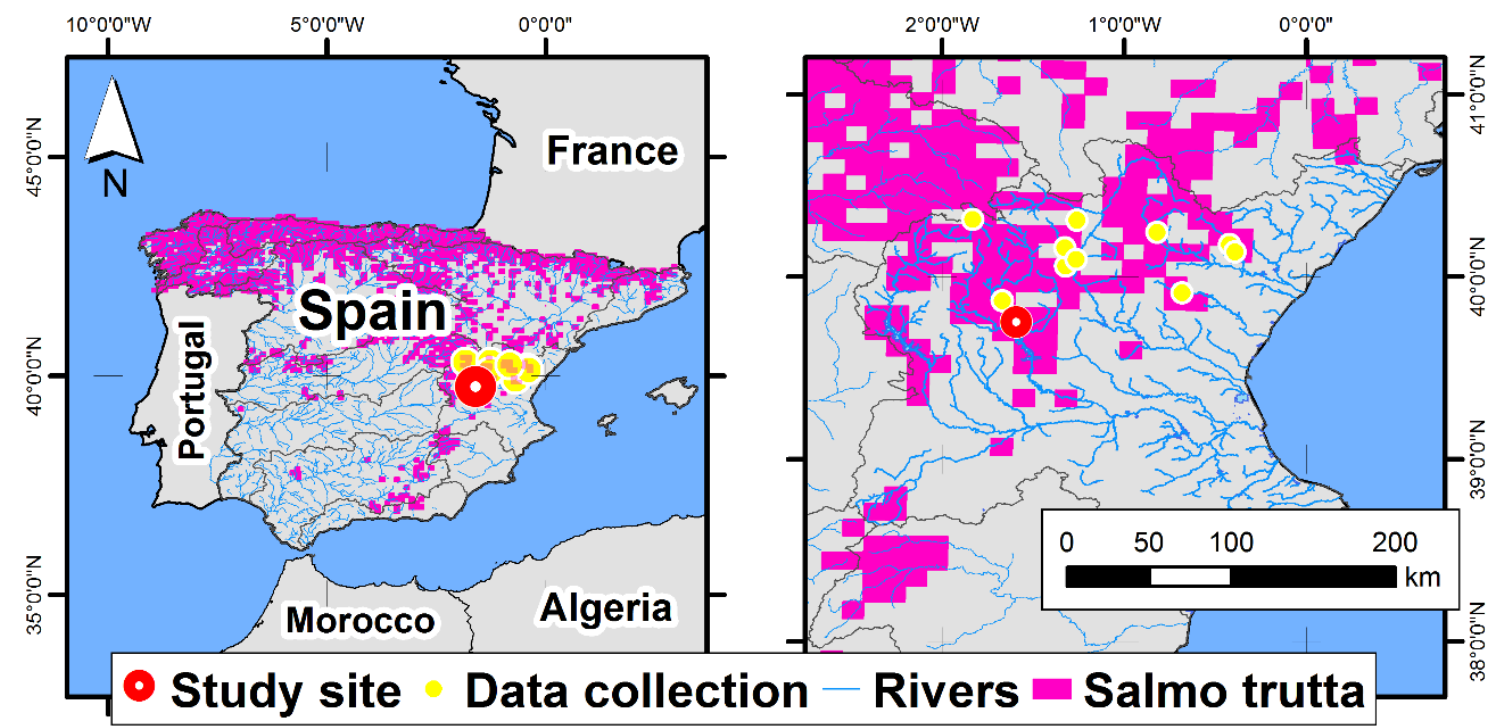

Fig. 1. Location of the study site and river segments sampled for data collection on habitat preferences for brown trout (Salmo trutta, L.) spawning. The coloured grid highlights the current brown trout distribution area (MAPAMA - Spanish government, 2017). 


\subsection{Microhabitat suitability modelling}

\subsubsection{Data collection}

The data-driven hydraulic module of the habitat suitability model (Fig. 6) was based on empirical data collected at the microhabitat scale (i.e., six measurements per redd) in several surveys within the period 2006-2016 (Fig. 1). The rivers were sampled during the spawning period - late autumn and winter (Elliott and Elliott, 2010) - covered most of the inhabited mountainous rivers of the Jucar River Basin district (34.4 km in total). Specifically, these were: the Argelita, Valbona and Villahermosa rivers (Mijares River Basin), the Palancia River, the Vallanca, Ebrón and Turia rivers (Turia River Basin) and the Jucar and the Cabriel rivers (Jucar River Basin); all of them at river segments of Strahler order 2 (Strahler, 1952).

The surveyors walked along the target river segments, from downstream to upstream, spotting trout redds. At each redd, two measurements were taken; one at the lowest elevation (i.e., the pit of the redd) and the other approximately in the centre of the redd and behind the pit (i.e., at the top of the tailspill) (Fig. 2). In addition, the surrounding area was surveyed at four points $1.5 \mathrm{~m}$ from the redd centre following a parallel and perpendicular axis to the river thalweg. Over the years, 331 redds were spotted which, considering the sampling protocol, lead to a dataset of 0.33 prevalence (i.e., the ratio of presence cases over the entire dataset) with 1986 data. 


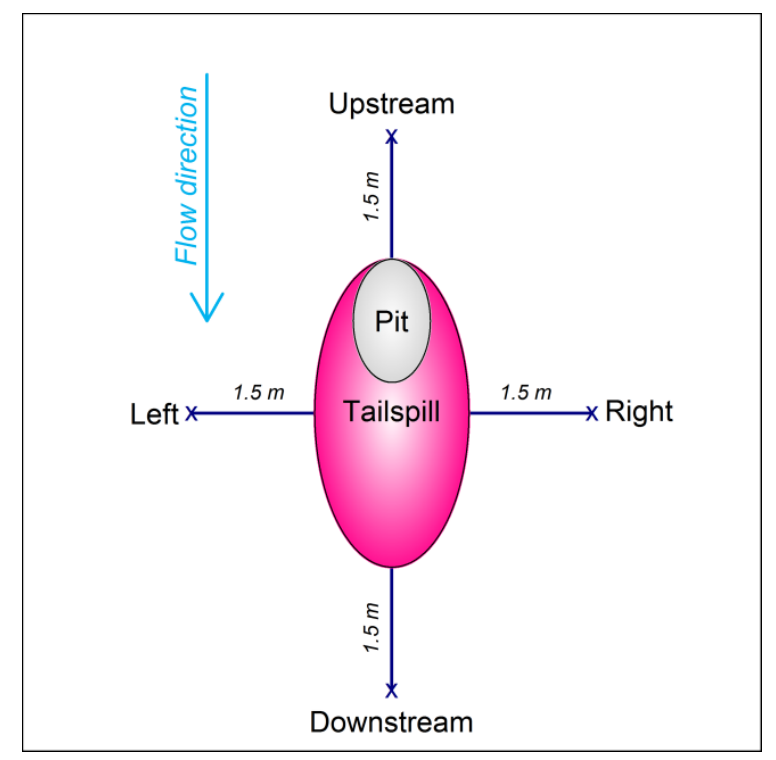

Fig. 2. Ellipse schematising an ideal brown trout redd and depicting the two locations measured for presence data (pit and tailspill) and the four surrounding locations recording absence data (left and right, upstream and downstream).

Depth, velocity and substrate were measured at each sampling point. Depth $(\mathrm{m})$ was measured with a wading rod to the nearest $\mathrm{cm}$ and velocity $(\mathrm{m} / \mathrm{s})$ was measured with an electromagnetic current meter (Valeport ${ }^{\circledR}$, UK) at $40 \%$ of the depth (Viganò et al., 2015). The percentage of each substrate class was visually estimated around each sampling point by employing a simplification of the American Geophysical Union size scale: silt ( $<62 \mu \mathrm{m})$, sand $(62 \mu \mathrm{m}-2 \mathrm{~mm})$, fine gravel $(2-8 \mathrm{~mm})$, gravel $(8-64 \mathrm{~mm})$, cobbles $(64-256 \mathrm{~mm})$, boulders (>256 mm) and bedrock in accordance with previous works (Muñoz-Mas et al., 2012). Finally, the substrate composition was converted into a single value through the substrate index (-), by combining the weighted percentages of each substrate type as follows: substrate index $=0.03 \cdot$ sand $\%+0.04 \cdot$ fine gravel $\%+0.05 \cdot$ gravel $\%+0.06$. cobble $\%+0.07 \cdot$ boulder $\%+0.08 \cdot$ bedrock $\%$ (Mouton et al., 2011) (Table 1 and Fig. 3). 
Table 1. Summary of the hydraulic characteristics recorded in each location sampled within the brown trout redd (presence data) and the four surrounding points (absence data).

\begin{tabular}{|c|c|c|c|c|c|c|c|c|}
\hline Class & Location & Variable & Min. & 1st Qu. & Median & Mean & 3rd Qu. & Max. \\
\hline \multirow{6}{*}{ Presence } & \multirow{3}{*}{ Pit } & Velocity $(\mathrm{m} / \mathrm{s})$ & 0.00 & 0.23 & 0.34 & 0.39 & 0.55 & 0.95 \\
\hline & & Depth (m) & 0.05 & 0.17 & 0.24 & 0.26 & 0.34 & 0.72 \\
\hline & & Substrate index (-) & 1.00 & 4.25 & 4.50 & 4.56 & 4.95 & 7.60 \\
\hline & \multirow{3}{*}{ Tailspill } & Velocity $(\mathrm{m} / \mathrm{s})$ & 0.00 & 0.23 & 0.35 & 0.40 & 0.58 & 1.14 \\
\hline & & Depth (m) & 0.05 & 0.17 & 0.24 & 0.26 & 0.33 & 0.90 \\
\hline & & Substrate index (-) & 1.00 & 4.30 & 4.55 & 4.58 & 4.80 & 7.40 \\
\hline \multirow{12}{*}{ Absence } & \multirow{4}{*}{ Upstream } & Velocity $(\mathrm{m} / \mathrm{s})$ & 0.00 & 0.18 & 0.29 & 0.34 & 0.48 & 0.97 \\
\hline & & Depth (m) & 0.07 & 0.17 & 0.26 & 0.27 & 0.34 & 0.75 \\
\hline & & Substrate index (-) & 0.00 & 3.40 & 4.40 & 3.83 & 5.00 & 8.00 \\
\hline & & Velocity $(\mathrm{m} / \mathrm{s})$ & 0.00 & 0.11 & 0.26 & 0.31 & 0.48 & 1.09 \\
\hline & \multirow[t]{3}{*}{ Right } & Depth (m) & 0.03 & 0.13 & 0.22 & 0.24 & 0.32 & 0.75 \\
\hline & & Substrate index (-) & 0.00 & 0.23 & 4.00 & 3.26 & 4.90 & 8.00 \\
\hline & & Velocity $(\mathrm{m} / \mathrm{s})$ & 0.00 & 0.24 & 0.40 & 0.44 & 0.62 & 1.19 \\
\hline & \multirow[t]{3}{*}{ Downstream } & Depth (m) & 0.05 & 0.15 & 0.23 & 0.25 & 0.33 & 0.82 \\
\hline & & Substrate index (-) & 0.00 & 3.16 & 4.38 & 3.82 & 5.00 & 8.00 \\
\hline & & Velocity $(\mathrm{m} / \mathrm{s})$ & 0.00 & 0.09 & 0.24 & 0.32 & 0.47 & 1.12 \\
\hline & \multirow[t]{2}{*}{ Left } & Depth (m) & 0.01 & 0.15 & 0.22 & 0.23 & 0.30 & 0.75 \\
\hline & & Substrate index (-) & 0.00 & 0.70 & 3.70 & 3.09 & 4.80 & 8.00 \\
\hline
\end{tabular}
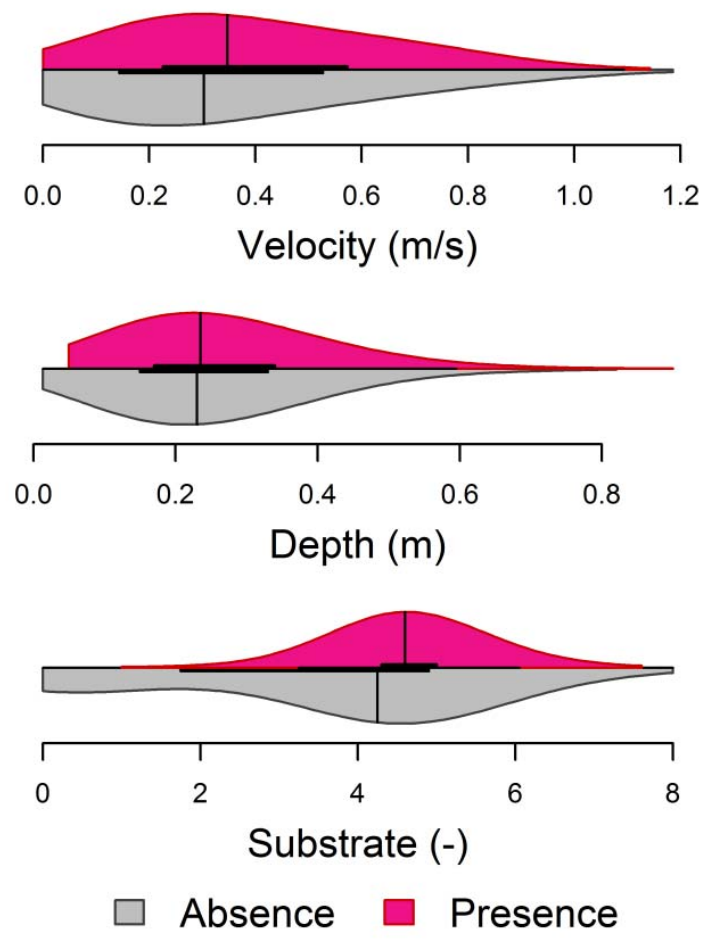
Fig. 3. Violin plots of the data collected on the hydraulic conditions of the sampled brown trout redds. Data appear discriminated by presence (redd pit and tailspill) and absence (surrounding area) respectively at the upper and the lower half. The vertical lines depict the median values.

\subsection{Fuzzy habitat suitability modelling}

\subsubsection{Hydraulic suitability module}

The microhabitat suitability model was developed by means of a presence-absence zeroorder Takagi-Sugeno-Kang (TSK) fuzzy rule-based system (Takagi and Sugeno, 1985). Fuzzy rule-based systems (e.g., TSKs) are based on Zadeh's seminal work (1965) and consist of a rule-base of antecedents and consequents (i.e., an ensemble of IF-THEN sequences called fuzzy rules) relating the different hydraulic conditions (Fig. 6). These hydraulic conditions are described by a few fuzzy sets - each one with its corresponding membership function $\mu(x)$ - named after linguistic labels (e.g., Low velocity) (Adriaenssens et al., 2004). The popularity of fuzzy logic relies on several complementary issues: fuzzy rule-based systems are universal approximators able to render any desired accuracy (Castro, 1995), with a low number of fuzzy sets they are interpretable (Hüllermeier, 2005), and this is not at the expense of complex mathematical structures (Muñoz-Mas et al., 2016d). In accordance with the last statement, a fuzzy rule-based system can be based on empirical data (i.e., data-driven) and subsequently be inspected, used and modified - on the basis of expert knowledge, scientific literature or new insights - to cover a wider range of environmental conditions (Mouton et al., 2008). The main difference of presenceabsence zero-order TSK fuzzy models, in comparison with the more popular MamdaniAssilian models (Mamdani, 1974), are the rule consequents (i.e., the THEN part), which consist of 1 or 0 , respectively, for presence and absence (e.g. IF velocity is Low and depth is High THEN 1). 
The optimisation of a TSK can be performed by simultaneously tuning the membership function parameters (i.e., the amplitude and overlapping of the fuzzy sets) and the rule consequents (e.g., Jang, 1993), although tuning the membership function is rare within studies based on the physical habitat simulation (e.g., Muñoz-Mas et al., 2016d; Fukuda, 2013). However, in accordance with the data collected (Fig. 3) and the theory around the use of convex hulls (Cornwell et al., 2006) to determine the $n$-dimensional hypervolume describing the ecological niche (sensu Hutchinson, 1957), we advocated the opposite approach. Therefore, three fuzzy sets and the shape of their membership functions were optimised while the rule-base was fixed (i.e., non-optimised) and only the rule consequent involving Medium velocity, Medium depth and Medium substrate depicted suitable conditions (i.e., THEN 1) (Table 2).

Table 2. Summary of the final fuzzy rules combining the hydraulic and water temperature suitability modules.

\begin{tabular}{|c|c|c|}
\hline Microhabitat suitability module & Water temperature suitability module & Consequent \\
\hline $\begin{array}{l}\text { IF Velocity is Low OR Depth is Low OR } \\
\text { Substrate index is Low }\end{array}$ & OR Water temperature is Low & THEN 0 \\
\hline $\begin{array}{l}\text { IF Velocity is Medium AND Depth is } \\
\text { Medium AND Substrate index is Medium }\end{array}$ & AND Water temperature is Medium & THEN 1 \\
\hline $\begin{array}{l}\text { IF Velocity is High OR Depth is High OR } \\
\text { Substrate index is High }\end{array}$ & OR Water temperature is High & THEN 0 \\
\hline
\end{tabular}

To enhance the reliability of the model from an ecological viewpoint, П-membership functions (Equation 2 and Fig. 4) were selected because trapezoidal and triangular membership functions render polyhedral convex hulls instead of smooth ones (Muñoz-Mas et al., 2016d). П-membership functions are defined by four parameters $\left(a_{m}, b_{m}, c_{m}\right.$ and $\left.d_{m}\right)$ and when $b_{m}$ equals $c_{m}$ the membership functions present a single maxima at this point. Based on previous studies (e.g., Fukuda, 2013), the latter structure, which provides a single optima, was selected (see Fig. 4). 


$$
\mu(x ; a, b, c, d)=\left\{\begin{array}{c}
0, x \leq a \\
2\left(\frac{x-a}{b-a}\right)^{2}, a \leq x \leq \frac{a+b}{2} \\
1-2\left(\frac{x-a}{b-a}\right)^{2}, a \leq x \leq \frac{a+b}{2} \\
1, b \leq x \leq c \\
1-2\left(\frac{x-c}{d-c}\right)^{2}, c \leq x \leq \frac{c+d}{2} \\
2\left(\frac{x-d}{d-c}\right)^{2}, \frac{c+d}{2} \leq x \leq d \\
0, x \geq d
\end{array}\right\}
$$

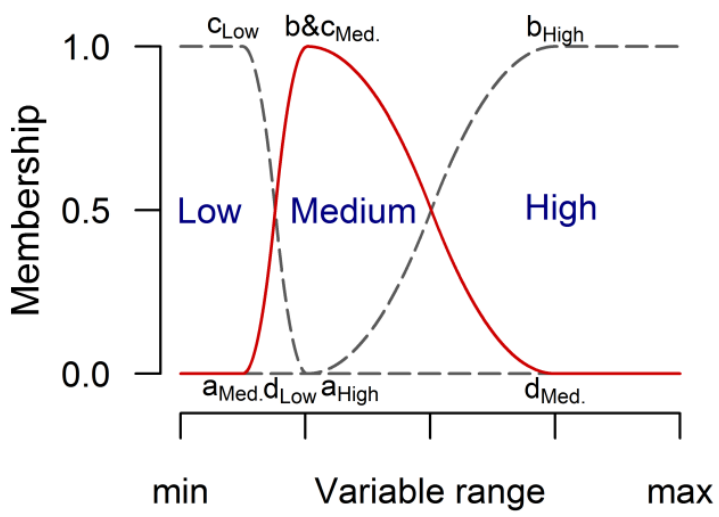

Fig. 4. Depiction and parameters $\left(a_{i}, b_{i}, c_{i}\right.$ and $\left.d_{i}\right)$ defining an asymmetric $П$-membership function.

The optimisation of the nine parameters of the membership functions, one per fuzzy set (Low, Medium and High) for the three input variables, was performed with Differential Evolution (DE) (Storn and Price, 1997). The DE is a kind of evolutionary algorithm particularly suited to optimise real-valued functions of real-valued parameters (Ardia et al., 2011; Mullen et al., 2011). Several potential solutions are encoded in real number strings (i.e., chromosomes) and the whole set corresponds to the population. Subsequently, the performance associated to each chromosome is calculated (termed 'fitness') and the evolution takes place by creating a new population, employing arithmetic operations, from the parent population members (Mullen et al., 2011). Then, only those offspring 
chromosomes that present better fitness substitute their parents, which iteratively finds better solutions (Ardia et al., 2011). Finally, the evolution halts if the maximum number of generations is achieved or if the algorithm is unable to find a better solution after a specified number of generations.

The optimisation was conducted with the $R$ package DEoptim (Ardia et al., 2011; Mullen et al., 2011) maximising a fitness function (Equation 3) especially addressed to stimulate overprediction (Sensitivity > Specificity) (Muñoz-Mas et al., 2016e, 2016c) because it has been stated to be more reliable from an ecological viewpoint than under-prediction (Mouton et al., 2010):

$$
\text { Fitness }=T S S+\min \{0, S n-S p\} ;(\text { Equation } 3)
$$

where Sn (Sensitivity) corresponds to the ratio of presences correctly classified (classification threshold at 0.5$), S p$ (Specificity) corresponds to the ratio of absences correctly classified and TSS (True Skill Statistic) to the sum of sensitivity and specificity minus one (i.e., $T S S=S n+S p-1$ ) (see Mouton et al., 2010). Although the model structure (i.e., number of fuzzy sets and rule consequents) was set beforehand, five-fold CrossValidation (CV) was performed in order to scrutinise TSK generalisation (Arlot and Celisse, 2010). Parameter settings of the optimisation were based on the recommendations described in Mullen et al. (2011) and the package's vignette (Table 3). Once the CV was completed, one single model was developed by averaging the five optimal vertices of each membership function (Fukuda et al., 2013) and it was subsequently modified to include the effect of the water temperature (see below). 
Table 3. Parameter settings of the Differential Evolution (DE) algorithm. Default values were used in the unlisted arguments.

\begin{tabular}{lll} 
Operator & Argument name & Setting \\
\hline Value to be reached & VTR & 1 \\
Evolving strategy & strategy & 2 \\
Population size & NP & $10 \times \#$ parameters \\
Maximum iterations allowed & itermax & $10 \times \#$ parameters \\
Crossover adaptation & $\mathrm{C}$ & 0.7 \\
Crossover probability & $\mathrm{CR}$ & 0.5 \\
Differential weighting factor & $\mathrm{F}$ & 0.8 \\
Relative convergence tolerance & reltol & 0.005 \\
Step tolerance & steptol & $5 \times \#$ parameters \\
\hline
\end{tabular}

\subsubsection{Water temperature suitability module}

Despite the lack of 'common garden' experiments on embryo miscarriage, the tolerance limits, optimal range for survival and developmental time proved to have little variation along latitudinal gradients (Ojanguren and Braña, 2003). In accordance, the TSK fuzzy model was modified - based on scientific literature - to account for the influence of water temperature on the overall suitability (Fig. 6). Low and high water temperature restrain embryo development and viability (Elliott and Elliott, 2010). Therefore, the three fuzzy sets scheme depicted above was also used to characterise the effect of water temperature (Fig. 4). An additional antecedent corresponding to water temperature was aggregated to the rule base while the only rule with a suitable consequent (i.e., THEN 1) remained that which included Medium fuzzy sets (i.e., Medium velocity, depth, substrate and Medium water temperature) (Table 2). An exhaustive review was performed to collect original studies on temperature effects (see Fig. 6 for the complete list of 13 references). The consulted documents rendered information of different nature and level of detail, such as several values on habitat suitability (e.g., Bovee, 1978), a number of mortality percentages at different temperatures (e.g., Réalis-Doyelle et al., 2016; Embody, 1934) or simply an optimal range (e.g., Moyle, 2002). Nevertheless, analogously to the membership to a fuzzy 
set, the suitability and the aforementioned percentages are formulated with values ranging from one to zero while the optimal range can be assimilated to one and the intolerable temperatures to zero. Therefore, these values and the membership degree were considered equivalent and the fuzzy sets were optimised - with the DE algorithm and the parameter settings described above - to minimise the difference between the reported values and the central membership function (i.e., that corresponding to Medium water temperature). In order to favour the more exhaustive studies, the fitness function consisted of the Mean Squared Error weighted by the number of independent data reported at each study (i.e., wMSE).

The resulting TSK fuzzy model, encompassing the three microhabitat variables (i.e., depth, velocity and substrate) and the water temperature, was used to assess 2501 alternative combinations of flow rate between $0-76.49 \mathrm{~m}^{3} / \mathrm{s}$, and of water temperature between $0-30$ ${ }^{\circ} \mathrm{C}$, which corresponded to 41 different flows based on its probability of occurrence and the whole temperature sequence between $0-30^{\circ} \mathrm{C}$ (at a rate of $0.5^{\circ} \mathrm{C}$ ) (Fig. 6). The habitat assessment for each combination was used to characterise the habitat available under the historical and climate change scenarios (see below).

\subsection{Hydraulic modelling}

The hydraulic simulation encompassed a reach of the Cabriel River of approximately $300 \mathrm{~m}$ in length. In a previous three-year study performed at the mesohabitat scale, 473 brown trout parr were observed during spring (Muñoz-Mas et al., 2016e; Vezza et al., 2015; Costa et al., 2012), which, given the usual dispersion rates, indicated successful brown trout reproduction in the area (Fausch and Northcote, 1992). Data collection and model development followed standard procedures (Jowett and Duncan, 2012). Thereby, the 
topographic data of the river channel and banks were collected using a Leica@ Total Station, simultaneously collecting data on the substrate composition by employing the scale described above (Fig. 5.). Three different campaigns were performed in three different flows (i.e., 3.32, 4.78 and $7.63 \mathrm{~m}^{3} / \mathrm{s}$ ); the Water Surface Elevation (WSE) was measured in each of them at a number of locations along the river reach to calibrate the hydraulic model. Finally, the necessary flow-elevation curve at the downstream-end cross-section was completed with an additional measurement at a rate of $33.87 \mathrm{~m}^{3} / \mathrm{s}$ and the stage of zero flow at $854.84 \mathrm{~m}$ a.s.I. (Fig. 5. A). The 2D hydraulic simulation was performed with River2D ${ }^{\odot}$ (Steffler and Blackburn, 2002) varying the bed roughness to adjust the outcomes to the measurements performed during the three sampled flow rates. The calibration was considered satisfactory when the mean of the residuals was below $5 \mathrm{~cm}$ (Muñoz-Mas et al., 2012). Subsequently, and based on the flow duration curve (Fig. 5. B), 41 uniformly distributed flows were simulated, which included the three flows surveyed during the aforementioned three-year study (Fig. 6).

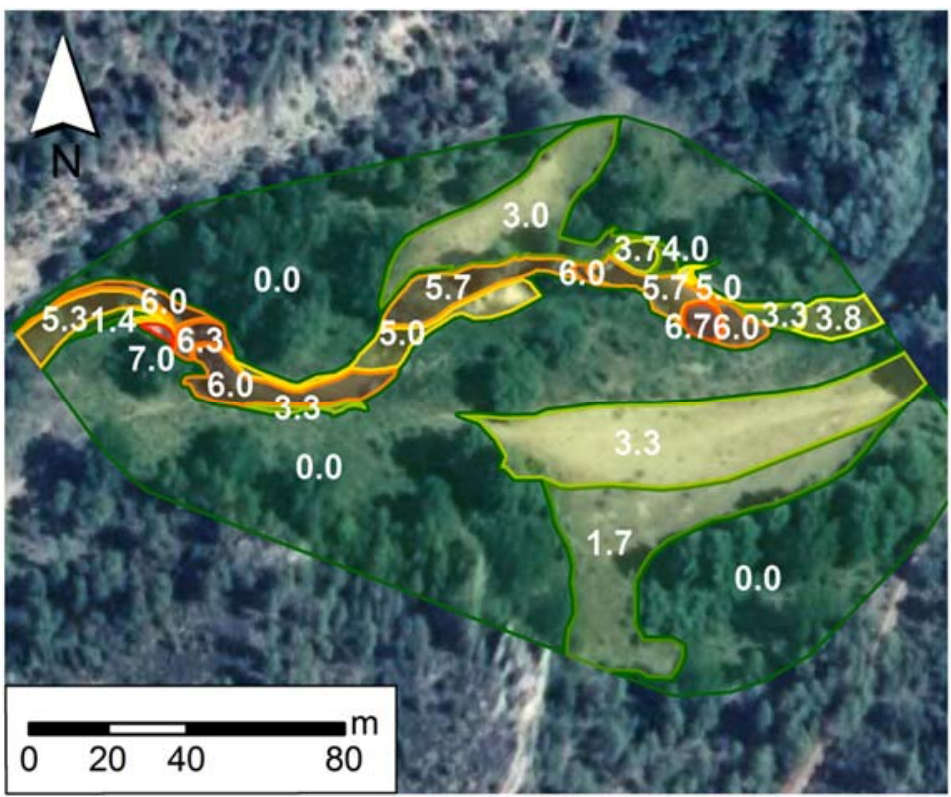

$$
\begin{gathered}
\text { Sub. index } \\
=0.0 \\
=1.4 \\
=1.7 \\
=3.0 \\
=3.3 \\
=3.3 \\
=3.7 \\
=3.9 \\
=4.0 \\
=5.0 \\
=5.3 \\
=5.7 \\
=6.0 \\
=6.3 \\
=6.7 \\
=7.0
\end{gathered}
$$
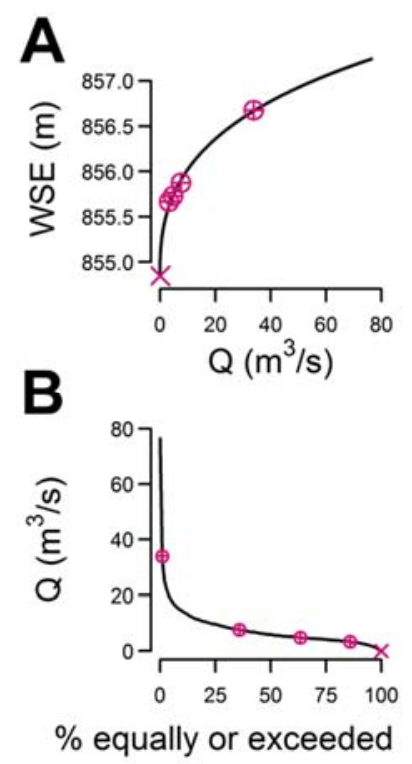

Fig. 5. General view of the study site and the distribution of the substrate index (-); zero means vegetation or silt and eight the coarsest substrate, i.e. bedrock. A) Flow-rate curve depicting the 
measured river flows (i.e., 3.32, 4.78, 7.63 and $33.87 \mathrm{~m}^{3} / \mathrm{s}$ ) and B) flow duration curve at the gauging station downstream of the site, depicting the sampled flows.

\subsubsection{Selection of the representative river reach}

Evaluating representative river segments permits a confident extrapolation of the conclusions to a broader area (Warrner et al., 2010). It is typically undertaken after selecting a shorter river reach with a similar proportion, in terms of area, of different flow types (i.e., shallow and fast, slow and deep, etc.) based on the habitat mapping of a longer river segment (Bovee, 1982). Using the concepts of this semi-quantitative approach, a smaller - numerically representative - part of the hydraulic model was selected (Fig. 6). The selected reach matched the mean water depth, velocity and substrate observed during the three-year study mentioned above (i.e., Muñoz-Mas et al., 2016e; Vezza et al., 2015; Costa et al., 2012), where a river segment longer than $1 \mathrm{~km}$ was surveyed once a year, providing data on the hydraulic conditions at the flow rates of $2.77,3.48$ and $5.58 \mathrm{~m}^{3} / \mathrm{s}$. The selected reach was encompassed in a polygon of four vertices $(\mathrm{X}, \mathrm{Y})$ that minimised the per cent difference between the simulated (shorter) and reference (longer) river sections that, simultaneously, maximised the selected area. The optimisation was performed with the DE algorithm and the parameter settings described above and the resulting area was that used to evaluate the climate change-induced changes in brown trout spawning habitats.

\subsection{Rainfall-runoff and water temperature modelling}

\subsubsection{Rainfall-runoff modelling}

The hydrological simulation was implemented through the HBV-light model (Seibert and Vis, 2012) (Fig. 6). This is a new version of the HBV conceptual model (Bergström, 1976), 
which consists of four routines (snow, soil, groundwater and routing) for simulating catchment flow rate, usually on a daily time step, based on time series of precipitation and air temperature as well as estimates of monthly long-term potential evaporation rates. In the snow routine, snow accumulation and snowmelt are computed by a degree-day method involving 5 parameters. In the soil routine, groundwater recharge and actual evapotranspiration are simulated as functions of actual soil water storage, using 3 parameters. In the response (or groundwater) routine, runoff is computed as a function of water storage (5 parameters). Finally, a triangular weighting function is used in the routing to simulate the runoff at the catchment outlet ( 1 parameter). The model was calibrated, using daily flow rate data from the gauging station at the basin outlet (near the study site), for the period 1978/79-2000/01 (mean annual flow at the gauging station $=7 \mathrm{~m}^{3} / \mathrm{s}$ ) by maximising the Nash-Sutcliffe Efficiency (NSE). Conversely, the validation was carried out for the Water temperature modelling for the 2001/02-2006/07 period.

\subsubsection{Water temperature modelling}

The input data for the water temperature modelling (Fig. 6) encompassed daily data from two different periods - 2006-2007 and 2012-2013 (842 days in total) - that were measured at the study site with two data loggers; a VEMCO T 8-bit Minilog TR® (Canada) for the former period, and a TruTrack WT-HR® (New Zealand) for the latter period. Following previous studies, three independent variables were selected: air temperature and flow rate of the same day and air temperature of the preceding day (Santiago et al., 2017; MuñozMas et al., 2016b; Piccolroaz et al., 2016). In the past, M5 model trees (Quinlan, 1992) rendered paramount results when addressing this task (Muñoz-Mas et al., 2016b). However, each machine learning approach has its merits and demerits, which may 
introduce uncertainty to predictions (Lin et al., 2015). Thus, assembling predictions of different models is gaining popularity because it may characterise and reduce the uncertainty of the final forecast (Ren et al., 2016). In accordance, the water temperature was modelled by means of an ensemble of three machine learning techniques, two piecewise linear approaches and one kernel-based approach; namely, M5 (Quinlan, 1992), Multi-Adaptive Regression Splines (MARS) (Fridedman, 1991) and Support Vector Regression (SVR) (Vapnik et al., 1997).

The models were developed employing the functions implemented in the $\mathrm{R}$ packages: Cubist (Kuhn et al., 2014), earth (Milborrow, 2016) and LinearizedSVR (Veeramachaneni and Williams, 2014) respectively for the M5 model tree, the MARS and the SVR. The hyperparameters for the three techniques were optimised, performing five-fold $\mathrm{CV}$, to maximise the NSE. Particularly, the optimal number of rules (i.e., the number of models in which the input space is divided) between 1 and 25 was sought for the M5 model tree. Similarly, for MARS, the optimal MinSpan parameter, which controls the minimum number of observations between the extremes of the piecewise linear models, and hence the final number of multilinear models, was also sought between 1 and 25 , while the remaining parameters were based on the package's manual and vignette (Milborrow, 2014, 2016).

Unlike standard implementations of SVR that are trained employing the complete dataset, LinearizedSVR rely on a set of prototypes as potential support vectors, which accelerate the model's convergence ( $\mathrm{Bi}$ and Bennett, 2003). In accordance, SVR with radial basis function kernels require the optimisation of four parameters: $C, \varepsilon$ (epsilon), $\gamma$ (gamma) and the final number of prototypes. The optimal number of prototypes was sought following a step-forward approach (see e.g., May et al., 2011), thus, their number was sequentially increased at a rate of one provided that the NSE improved. In addition, at each iteration, the optimal parameters between 0-2000 for the parameter $C$ and between $0-5$ for epsilon were 
optimised with the DE algorithm whereas the gamma parameter was internally optimised with the function sigma.est, implemented within the corresponding package (Caputo et al., 2002). Therefore, for each number of prototypes tested an optimisation with DE was performed.

Once the optimal hyperparameters were determined for each technique, a single model was trained - employing the complete dataset - (Fukuda et al., 2013), which was fed with the historical and climate change air temperature and flow time series. The final water temperature was calculated averaging the three forecasts. The complete list of the parameter settings for the three machine learning techniques can be found in Appendix A.

\subsubsection{Climate change scenarios}

The Representative Concentration Pathways (RCPs) 4.5 (cautious) and 8.5 (pessimistic) are currently the assumed standards in climate change studies performed at a daily timestep (e.g., Muñoz-Mas, Lopez-Nicolas, et al., 2016; Santiago et al., 2017). The RCP 4.5 is a scenario in which total radiative forcing peak around 2040 at $4.5 \mathrm{~W} / \mathrm{m}^{2}$ and then decline (Thomson et al., 2011). Conversely, the RCP 8.5 predicts a higher value (i.e., $8.5 \mathrm{~W} / \mathrm{m}^{2}$ ) because it depicts a steady increase in greenhouse gas concentration throughout the century, thus ending with the highest concentration levels (Riahi et al., 2007).

The future projections for the short (2011-2040) and the mid-term (2041-2070) were obtained from a combination of Global Climate Models (GCMs) and Regional Climate Models (RCMs) (Fig. 6). Since the GCMs scale is not suitable to characterise impacts at the regional and local level (IPCC, 2014), it was necessary to use downscaling techniques to build RCMs (Fig. 6). Three different GCM-RCM combinations were used (Table 4) from the 
CORDEX project, which aims to improve the downscaling process for different regions of the world (Christensen et al., 2014).

Table 4. Combinations of Global Climate Models (GCMs) and Regional Climate Models (RCMs) implemented in this study (source CORDEX, Christensen et al., 2014).

\begin{tabular}{lccc} 
MCG/MCR & SMHI-RCA4 & KNMI-RACMO22E & CLMcom-CCLM4-8-17 \\
\hline ICHEC-EC-EARTH & $X$ & $X$ & \\
MPI-M-MPI-ESM-LR & & & $X$ \\
\hline
\end{tabular}

The bias of climate model outputs (i.e., the difference between the modelled and observed values) must be corrected before using these results for specific purposes. In accordance, the "quantile mapping" method ( $\mathrm{Li}$ et al., 2010) through the R package "qmap" (Gudmundsson et al., 2012) was applied to the raw data. Once the variables were corrected, the future projections were used to feed the rainfall-runoff model and, subsequently, the temperature model. The differences of the median values between the historical and the future climate change scenarios for the period from 15 November-15 January, which corresponds to the spawning period in the Mediterranean part of the Iberian Peninsula (Gauthey et al., 2015), were compared with the Bayesian test implemented within the $\mathrm{R}$ package BEST, which provides credible values of the mean, median and standard deviation to infer their differences (Kruschke, 2013).

\subsection{Climate change-induced degradation in the spawning habitat}

The changes in the spawning habitat quantity and quality were quantified after Habitat Duration Curves (HDCs) (Milhous et al., 1990). They are very useful to evaluate changes in the frequency and duration of the suitable habitat in a study site (Muñoz-Mas et al., 2016b), which is summarised in a single value per flow rate. Therefore, they go beyond differences 
between instantaneous conditions and allow scientists to discern the long-term impact of different scenarios and the existence of bottlenecks affecting the activity scrutinised (Parasiewicz, 2008; Capra et al., 1995).

Several indices exist to summarise the habitat suitability of the entire river segment, although the Weighted Usable Area (WUA) (Bovee et al., 1998) is by far the most common (Payne, 2003). It corresponds to the aggregation of the area of each simulation cell (e.g. pixel) weighted by the corresponding suitability (i.e., the output of the TSK fuzzy model after evaluating the velocity, depth, substrate and water temperature of the simulation cell). However, given the mathematisation of the index, a huge amount of low quality habitat may render similar total value as a small area of highly suitable habitat (Person et al., 2014). To avoid these potentially misleading results, the Suitable Area (SA), which corresponds to the sum of the areas where the models predicted presence (Suitability $>0.5$ ) was also calculated (Muñoz-Mas et al., 2016b; Person et al., 2014).

The HDCs are built in a sequential procedure (Capra et al., 1995; Milhous et al., 1990). First, the aforementioned indicator about the suitability of the habitat available is calculated for each of the assessed combinations of flow rate and water temperature (2501 combinations in total). Usually, only hydraulics are assessed (e.g., Boavida et al., 2014; Muñoz-Mas et al., 2012); therefore, univariate habitat suitability vs flow curves are typically developed and upon these curves the values of the global indicator are interpolated employing the sequence of running flows for the different scenarios - which eventually become the Habitat Time Series (HTS) (i.e., the temporal sequence of WUA and SA) (Milhous et al., 1990). However, in this study, hydraulics and temperature were simultaneously considered; thus, we present habitat vs flow rate and water temperature surfaces. Correspondingly, the HTS were calculated by interpolating the different paired values of flow rate and water temperature of the historical and climate change scenarios, 
both over the WUA-related and the SA-related surfaces, and the HDCs were calculated by exclusively employing the data comprised between spawning period (15 November-15 January). The HDCs depict the proportion of time that any given value of WUA and SA is exceeded; consequently, when a given curve appears below the historical HDC, it indicates impoverished habitat conditions compared to the reference historical HDC. The cumulated area below the corresponding HDC was used to calculate the climate change-induced degradation in brown trout spawning habitat as a per cent difference. 


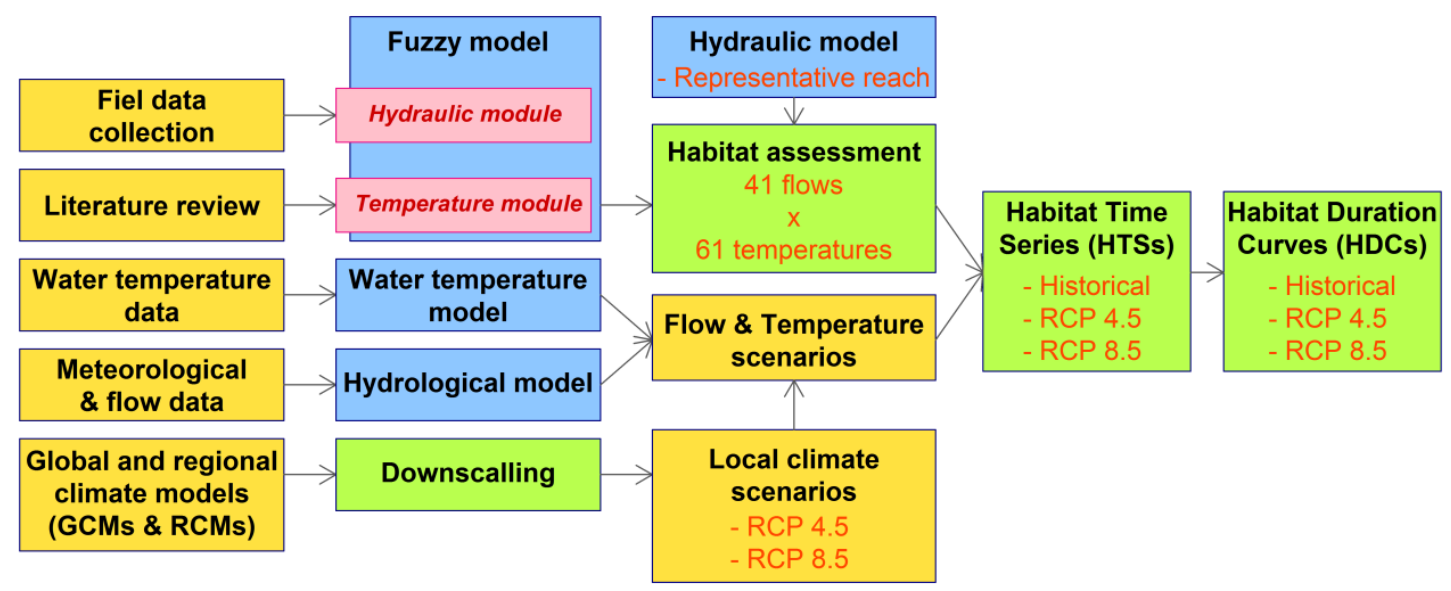

Fig. 6. Flowchart depicting the process followed to predict the brown trout (Salmo trutta L.) spawning habitat degradation induced by climate change.

\section{Results}

\subsection{Habitat suitability modelling}

The generalisation of the data-driven hydraulic suitability module of the zero-order presence-absence Takagi-Sugeno-Kang (TSK) fuzzy rule-based system - optimised with Differential Evolution (DE) - was considered acceptable because the performance criteria on the test and the training datasets did not markedly differ (Table 5). The Sensitivity (Sn) and Specificity (Sp) were close to, or above, 65\% and the weighted Mean Squared Error (wMSE) indicated an overall accuracy above 75\%, although the True Skill Statistics (TSS) presented moderate values. 
Table 5. Mean values of the performance criteria calculated for the training and test datasets after five-fold Cross Validation (CV): Fitness, True Skill Statistics (TSS), Sensitivity (Sn), Specificity (Sp) and weighted $\left(1-\right.$ prevalence $\left._{\text {class }}\right)$ Mean Squared Error (WMSE).

\begin{tabular}{llllll} 
& Fitness & TSS & Sn & Sp & wMSE \\
\hline Training & $0.31 \pm 0.01$ & $0.31 \pm 0.01$ & $0.66 \pm 0.01$ & $0.65 \pm 0.01$ & $0.24 \pm 0.00$ \\
Test & $0.24 \pm 0.06$ & $0.26 \pm 0.05$ & $0.62 \pm 0.03$ & $0.64 \pm 0.03$ & $0.24 \pm 0.02$ \\
\hline
\end{tabular}

The fuzzy sets and membership functions of the hydraulic suitability module exhibited great stability. Consequently, the five-fold Cross-Validation (CV) rendered similar patterns for every fold (Fig. 7). The final TSK fuzzy model presented the optimum for velocity at 0.22 $\mathrm{m} / \mathrm{s}$, for depth at $0.14 \mathrm{~m}$ and for substrate index at 4.92 , which nearly corresponds to gravel. Although the model structure allowed unsuitable conditions at the extreme of the sampled ranges, the membership functions gently decrease for velocity and depth but not for the substrate index; thus the lower and higher extremes, which correspond to vegetated silt and bedrock, respectively, were considered completely unsuitable.

Concerning water temperature, the bibliographic review depicted in Fig. 7 (13 references in total) highlights the great diversity in the reported information, which is especially remarkable with regard to the lower water temperatures (i.e., below $5^{\circ} \mathrm{C}$ ). Conversely, a general pattern was observed for the higher temperatures (i.e., above $5{ }^{\circ} \mathrm{C}$ ), thus the highest concentration appeared around $7.5^{\circ} \mathrm{C}$ and the decrease of the suitability was indicated to occur between $10-15^{\circ} \mathrm{C}$, although the amplitude of the tolerance was relatively high. In accordance, the optimal value of the central fuzzy set appeared displaced towards warmer temperatures and was set at $9.09^{\circ} \mathrm{C}$, whereas the upper threshold was set at 15 ${ }^{\circ} \mathrm{C}$. The water temperature is expected to rise (see below); therefore, the uncertainty on the lower temperatures was considered negligible. 

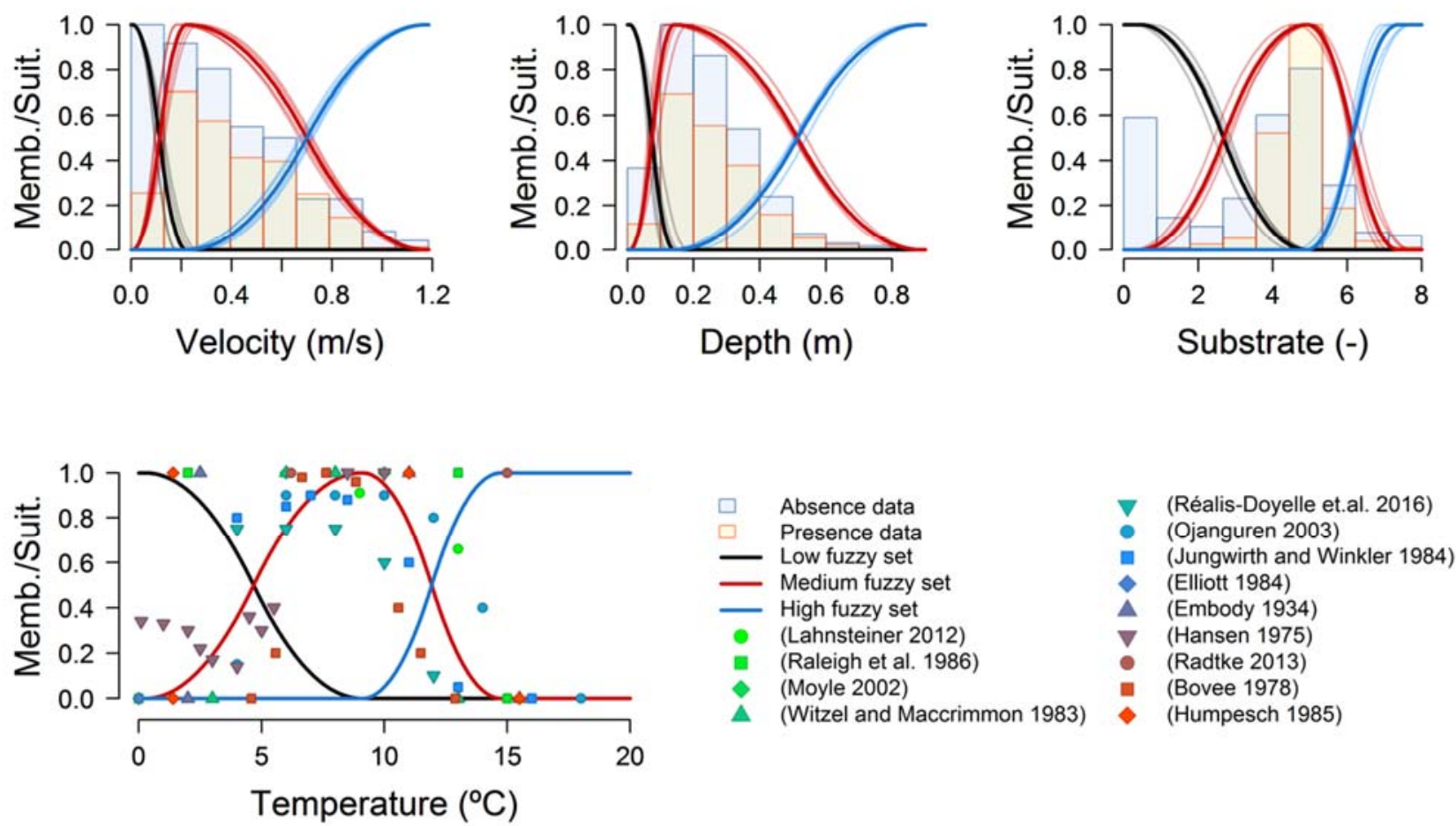

Fig. 7. Depiction of the fuzzy sets and membership functions of the zero-order presence-absence Takagi-Sugeno-Kang fuzzy rule-based system optimised with Differential Evolution. The upper sequence depicts the data-driven hydraulic suitability module (velocity, depth and substrate) based on empirical data, and the lower panel the literature-based water temperature module based on the adjacent list of 13 references.

\subsection{Selection of the representative river reach}

The hydraulic model encompassed a sinuous sequence of four riffles and pools, which is characterised by the alternation of fast-shallow and slow-deep areas (Fig. 8). This channel geometry restricted the suitable habitat to the inner side of the river bends. The largest area maximising the representative reach for the simulation was obtained - with DE - after removing a small part in the eastern extreme of the hydraulic model (Fig. 8, grey area). The largest mean difference occurred for depth (approximately 25\%), although the largest difference at a specific flow occurred with the substrate index collected at $5.56 \mathrm{~m}^{3} / \mathrm{s}\left(Q_{53}\right)$, 
which was above $40 \%$ (Table 6). Nevertheless, the mean difference of the three flow rates and variables was slightly above $12 \%$; thus, it was considered appropriate.
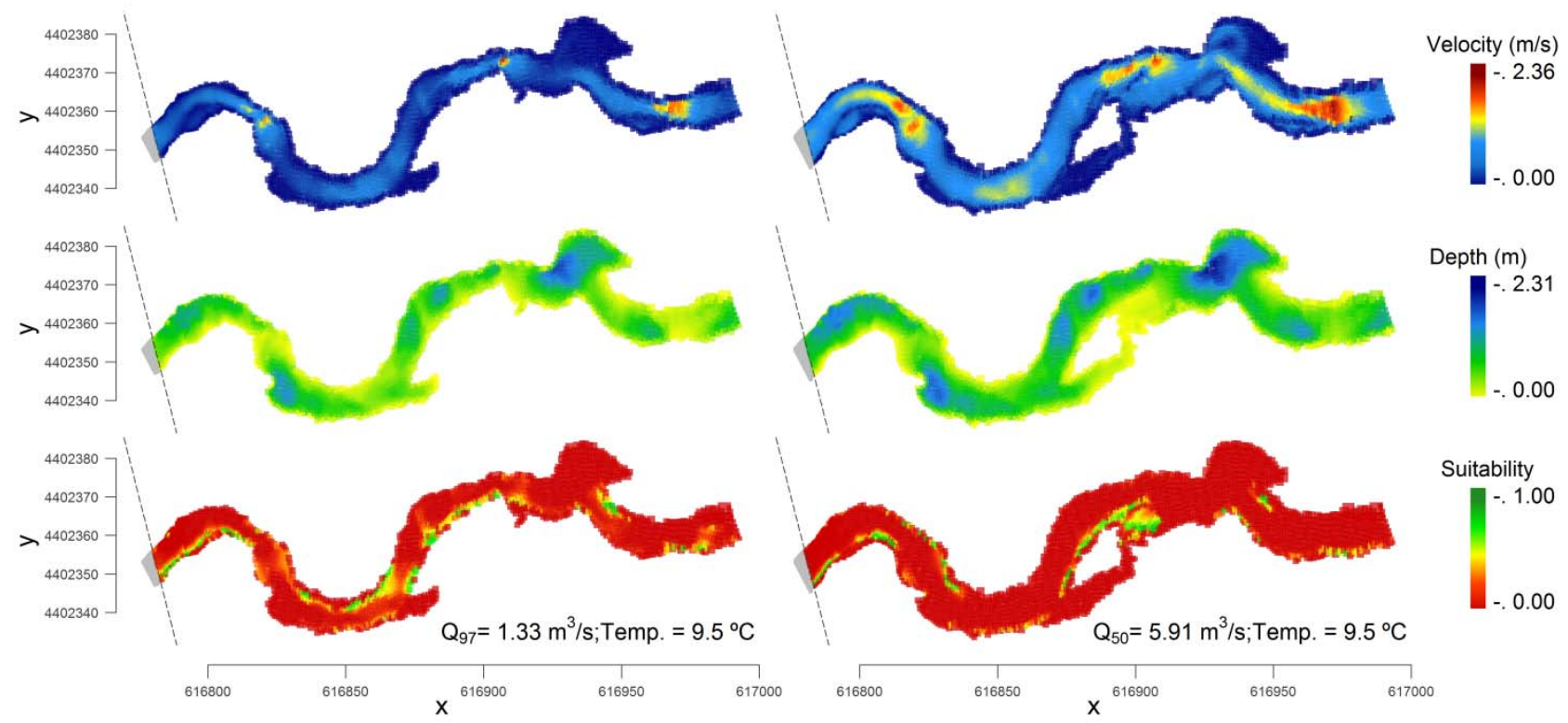

Fig. 8. Plan view of the simulated velocity (upper sequence), depth (mid sequence) and habitat suitability (lower sequence) for the minimum simulated flow $\left(Q_{97}=1.33 \mathrm{~m}^{3} / \mathrm{s}\right)$ and the median flow $\left(Q_{50}=5.91 \mathrm{~m}^{3} / \mathrm{s}\right)$. In both cases the water temperature was set to $9.5^{\circ} \mathrm{C}$. The representativeness of the simulated river segment was maximised, with Differential Evolution, removing the eastern extreme of the hydraulic model (in grey).

Table 6. Per cent difference between the velocity, depth and substrate index collected at the three flow rates surveyed during the three-year study used as reference - river segment $(>1 \mathrm{~km})$ - and the selected part of the hydraulic model.

\begin{tabular}{llll} 
Reference flow & Depth & Velocity & Substrate \\
\hline Q91 $=2.77 \mathrm{~m} 3 / \mathrm{s}$ & $25.34 \%$ & $-8.76 \%$ & $5.88 \%$ \\
Q83 $=3.48 \mathrm{~m} 3 / \mathrm{s}$ & $17.25 \%$ & $5.49 \%$ & $-5.37 \%$ \\
Q53 $=5.58 \mathrm{~m} 3 / \mathrm{s}$ & $30.93 \%$ & $2.38 \%$ & $41.35 \%$ \\
\hline
\end{tabular}




\subsection{Habitat assessment}

The surface depicting Weighted Usable Area (WUA) vs flow rate and water temperature, and the corresponding surface based on the Suitable Area (SA) depicted similar patterns (Fig. 9). With regard to the flow rate, the surface presented one maximum for the first effective simulated flow $\left(Q=1.33 \mathrm{~m}^{3} / \mathrm{s}\right)$ because it provided the largest instream suitable habitat (Fig. 8). In accordance with the fuzzy sets and their membership functions (Fig. 7), the suitability abruptly decreased as the assessed flow increased. Then, it depicted an almost constant plateau up to $33.87 \mathrm{~m}^{3} / \mathrm{s}\left(\mathrm{Q}_{10}\right)$ where the WUA rapidly rose to the maximum value, because for this and subsequent flow, the gravel in the southern floodplain is flooded (see Fig. 5). Nevertheless, the frequency of occurrence of these flows is extremely low (Fig. 5. B). Concerning the water temperature, both surfaces presented the highest values, for both WUA and SA, at $9.5^{\circ} \mathrm{C}$, which corresponded to the simulated temperature nearest to the optimal value (i.e., $9.09{ }^{\circ} \mathrm{C}$ ). However, the WUA surface presented a gentle decrease, either toward lower $\left(0^{\circ} \mathrm{C}\right.$ ) or higher temperatures (up to 15 ${ }^{\circ} \mathrm{C}$ ), which mimicked the central fuzzy set for water temperature. Conversely, the SA surface presented an abrupt decrease beyond 4.67 and $11.92{ }^{\circ} \mathrm{C}$ due to the classificatory nature of this index. 

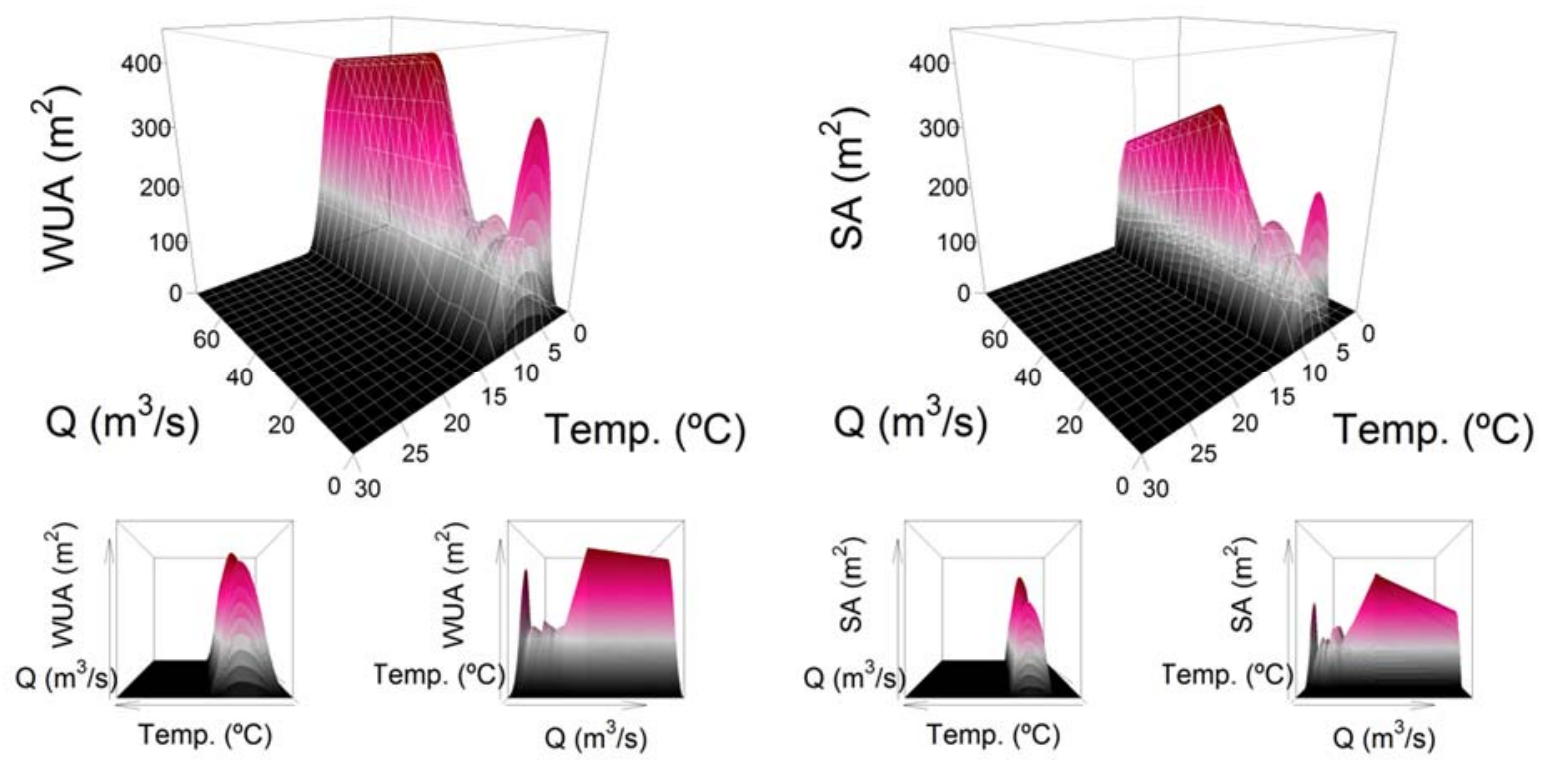

Fig. 9. Depiction of the Weighted Usable Area (WUA) vs flow rate $(\mathrm{Q})$ and water temperature (Temp.) surface based on the 2501 alternative combinations of flow rate $\left(0-76.49 \mathrm{~m}^{3} / \mathrm{s}\right)$ and water temperature $\left(0-30^{\circ} \mathrm{C}\right)$ (left) and Suitable Area (SA) vs flow rate $(\mathrm{Q})$ and water temperature (Temp.) surface base on the same combinations (right).

\subsection{Rainfall-runoff and water temperature modelling}

After the optimisation of the 14 parameters (Table 7 ) the rainfall-runoff models exhibited great generalisation because the Nash-Sutcliffe Efficiency (NSE) index for validation was of 0.81, whereas the NSE obtained during calibration was of 0.77 . In accordance with the good performance, the hydrological model mimicked the flow regime but it did not reproduce the daily or sub-daily operations of the small reservoir located immediately upstream the gauging station (i.e., Bujioso Reservoir) (Fig. 10, lower panel). Therefore, the predictions of this model, over the historical and the climate change scenarios, were considered suitable for comparison as reference (the former), and altered (the latter). Nevertheless, this and subsequent results based on the restoration of the altered data series into the natural flow regime, which lead to analogous conclusions, can be found in Appendix B. 
Table 7. Resulting parameters in the calibration of the hydrological model HBV-light.

\begin{tabular}{|c|c|c|c|c|}
\hline Routine & Parameter & Unit & Description & Value \\
\hline \multirow[t]{5}{*}{ Snow } & TT & ${ }^{\circ} \mathrm{C}$ & $\begin{array}{l}\text { Threshold temperature, below which } \\
\text { precipitation occurs as snow, and above at } \\
\text { which snow melt starts }\end{array}$ & -5 \\
\hline & CFMAX & ${ }^{\mathrm{m}} \mathrm{C} / \mathrm{day}$ & Degree-day factor & 12 \\
\hline & SFCF & - & Snowfall correction factor & 0.90 \\
\hline & CFR & - & Refreezing coefficient & 0.05 \\
\hline & $\mathrm{CWH}$ & - & Water holding capacity & 0.05 \\
\hline \multirow[t]{3}{*}{ Soil } & FC & $\mathrm{mm}$ & Maximum soil moisture storage & 365.78 \\
\hline & LP & - & $\begin{array}{l}\text { Soil evaporation threshold, above which actual } \\
\text { evapotranspiration } \quad \text { reaches } \\
\text { evapotranspiration }\end{array}$ & 0.80 \\
\hline & BETA & - & $\begin{array}{l}\text { Shape coefficient, which determines the relative } \\
\text { contribution to runoff from rain or snowmelt }\end{array}$ & 1.94 \\
\hline \multirow[t]{5}{*}{ Response } & $\mathrm{K}_{0}$ & 1/day & Storage (recession) coefficient for storage box 0 & 0.10 \\
\hline & $\mathrm{K}_{1}$ & 1/day & Storage (recession) coefficient for storage box 1 & 0.06 \\
\hline & $\mathrm{K}_{2}$ & 1/day & Storage (recession) coefficient for storage box 2 & 0.006 \\
\hline & PERC & $\mathrm{mm} /$ day & $\begin{array}{l}\text { Maximum percolation rate from upper to lower } \\
\text { storage box }\end{array}$ & 1.83 \\
\hline & UZL & $\mathrm{mm}$ & $\begin{array}{l}\text { Threshold above which flow is generated from } \\
\text { the upper zone }\end{array}$ & 67.39 \\
\hline Routing & MAXBAS & day & Length of weighting function & 2.43 \\
\hline
\end{tabular}




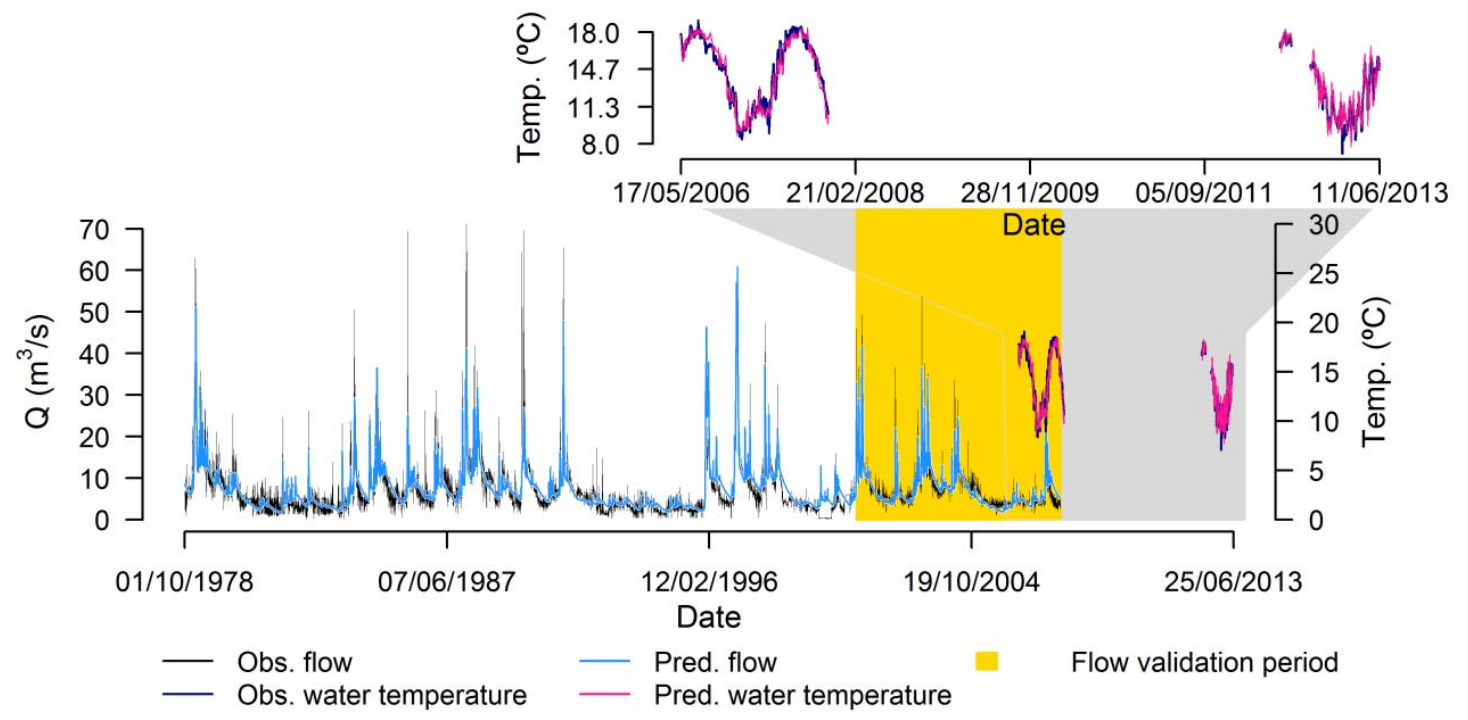

Fig. 10. Rainfall-runoff model and water temperature model agreement between the observed and predicted time series. The gold background indicates the period used for validation of the rainfallrunoff model. The grey background area highlights the time series of water temperature; the agreement between both time series is depicted in detail in the upper plot.

The ensemble of three machine learning techniques achieved paramount performance and the aggregate prediction mimicked accurately the available data on water temperature (Fig. 10, upper panel). The three techniques displayed almost the same performance (NSE values); $0.94 \pm 0.01,0.94 \pm 0.01$ and $0.94 \pm 0.00$, with the M5 model tree, the Multi-Adaptive Regression Splines (MARS) and the Support Vector Regression (SVR), respectively. Consequently, the three forecasts were averaged in order to feed subsequent analyses.

\subsection{Precipitation, flow rate and air and water temperature changes under the RCPs 4.5 and 8.5 in the short and mid terms}

The downscaled climate change scenarios predicted a general decrease in the daily rainfall and an increase in the air temperature, which resulted in lower flow rates and rising water temperatures (Fig. 11). This general picture is exacerbated in the mid-term scenarios and, 
particularly, for the Representative Concentration Pathway (RCP) 8.5 (i.e., pessimistic scenario). During the trout spawning period, the relevant changes in the median values (after the Bayesian test) determined a maximum decrease in the winter rainfall of $61 \%$ and a maximum air temperature increase of $58 \%$, both for the RCP 8.5 and the mid-term horizon. Nevertheless, the mean expected changes for the remaining scenarios and time horizons were more benevolent, corresponding to approximately $40 \%$ in both cases. These changes were not directly translated to the median flow rate and water temperature, which appeared buffered. In accordance, the decrease in the flow rate will be around $20 \%$, although the prediction for the RCP 8.5 and the mid-term horizon surpassed $24 \%$. The changes predicted for the water temperatures were less dramatic. Therefore, the mean increase in the median values will be approximately $10 \%$, except for the most pessimistic scenario and time-horizon, which will involve an increase slightly above $15 \%$ (RCP 8.5 Mid.). 

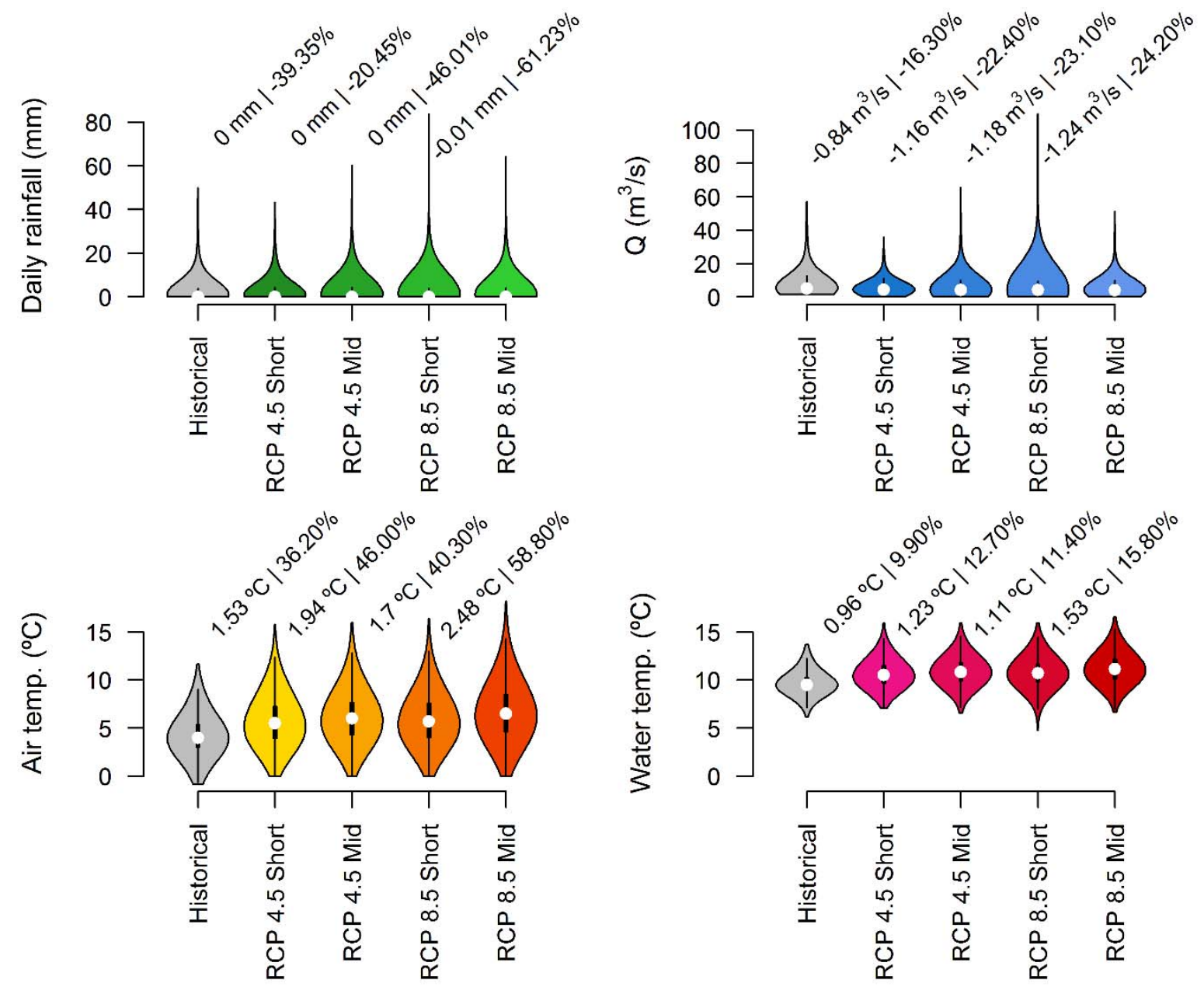

Fig. 11. Violin plots depicting the historical and expected absolute values of rainfall, river flow rate, air temperature and water temperature during spawning period (15 November-15 January) for the two temporal horizons (short: 2011-2040 and mid: 2041-2070) per Representative Concentration Pathway (RCP) (RCP 4.5 and 8.5). The differences on median values (absolute value and percentage) are tagged above.

\subsection{Climate change-induced degradation in the spawning habitat}

The predicted rise in the water temperature will not be compensated by the lower expected flows, which increase the suitability related to hydraulics (Fig. 7 and Fig. 8). In accordance with the habitat vs flow rate and water temperature surfaces, the Habitat Duration Curves (HDCs), either based on the WUA or the SA, presented similar aggregation patterns (Fig. 12). The predictions indicated that the study site will present at least some marginally 
suitable microhabitat (WUA $>0 \mathrm{~m}^{2}$ ) almost $100 \%$ of the analyses days (i.e., percentage of exceedance of the 0 WUA was close to $100 \%$ ). However, the Historical series always exceeded this value during the spawning period while during the climate change scenarios it will be not. On the contrary, the analysis based on the SA indicated that, historically, brown trout has found suboptimal conditions for spawning during $5 \%$ of the spawning period. The frequency of this situation will rise most during the mid-term of the RCP 8.5 , because it will not be surpassed during $30 \%$ of days. The remaining scenarios predicted an inferior frequency of null SA, on approximately $20 \%$ of days.

The per cent comparison of the difference between the cumulated areas below the HDCs predicted the largest decrease for the RCP 8.5 and the mid-term horizon, which corresponded to $27.6 \%$ and $48.7 \%$ for the WUA and SA, respectively (Table 8 ). Conversely, the remaining scenarios and time horizons indicated similar decreases for each index. The HDCs based on the WUA indicated that the decrease will be near $16 \%$, whereas those based on the SA showed a larger decrease, up to $35 \%$.

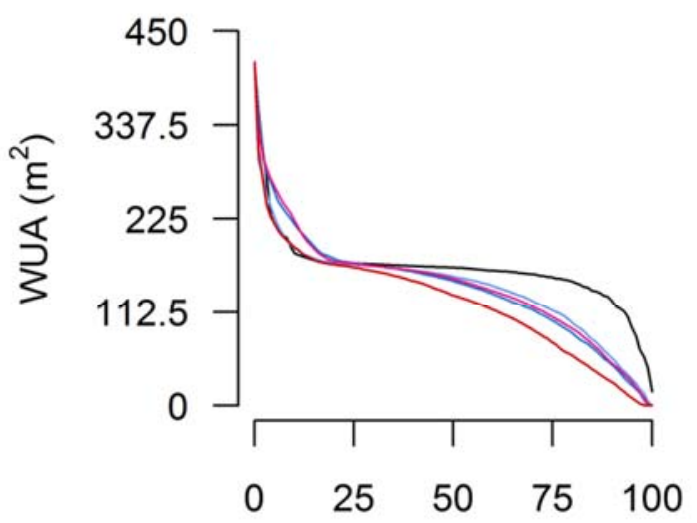

$\%$ equally or exceeded

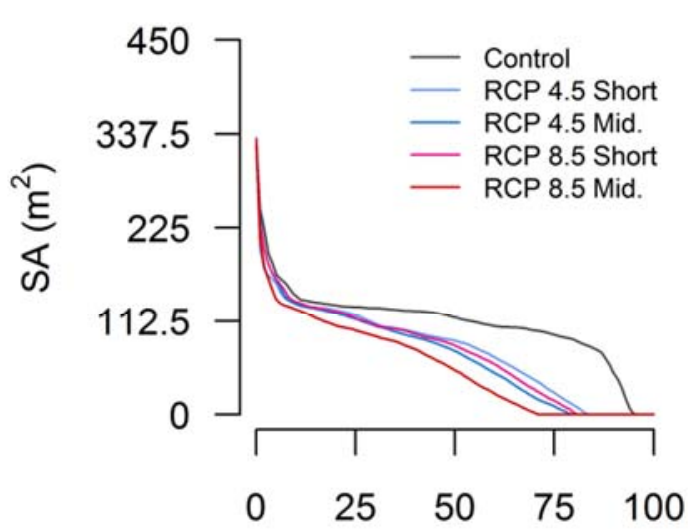

$\%$ equally or exceeded

Fig. 12. Habitat Duration Curves (HDCs) during spawning period (15 November-15 January) for the two temporal horizons (short: 2011-2040 and mid: 2041-2070) per Representative Concentration Pathway (RCP) (RCP 4.5 and 8.5) and the historical regimes of flow rate (hydraulics) and water 
temperature (reference) based on the Weighted Usable Area (WUA) (left panel) and the Suitable Area (SA) (right panel).

Table 8. Per cent difference between the cumulated area below the Habitat Duration Curves (HDCs) for the two temporal horizons per Representative Concentration Pathway (RCP) (i.e., RCP 4.5 and 8.5 ) and the historical regimes of flow rate (hydraulics) and water temperature (reference); based on Weighted Usable Area (WUA) and Suitable Area (SA).

\begin{tabular}{lll} 
Scenario/horizon & WUA $\left(\mathrm{m}^{2}\right)$ & $\mathrm{SA}\left(\mathrm{m}^{2}\right)$ \\
\hline RCP 4.5 Short & $-16.2 \%$ & $-32.1 \%$ \\
RCP 4.5 Mid. & $-16.2 \%$ & $-36.7 \%$ \\
RCP 8.5 Short & $-15.4 \%$ & $-34.2 \%$ \\
RCP 8.5 Mid. & $-27.6 \%$ & $-48.7 \%$ \\
\hline
\end{tabular}

\section{Discussion}

A fuzzy model combining a literature-based and a data-driven module has been used as the central element to predict the brown trout spawning habitat degradation in a segment of the Cabriel River under two different climate change scenarios and time horizons. Although this combined modelling approach was considered feasible (Mouton et al., 2008), to the best of our knowledge, it had not been reported before. In accordance, this approach proved suitable to adapt fuzzy habitat suitability models taking into account knowledge from different sources and nature. Therefore, adjusting the input variables and the corresponding fuzzy membership functions and rules should permit fuzzy models to perform properly in river segments with impoverished or extirpated populations (Muñoz-Mas et al., 2016d) or where certain environmental conditions are unavailable (e.g., deep microhabitats) and the adequate sampling is no longer possible. Consequently, this kind of hybrid models should be especially indicated for river segments where no profitable surveys can be performed at a reasonable cost. The fuzzy model was optimised with Differential Evolution (Storn and 
Price, 1997). The DE algorithm was involved in a number of subsequent optimisations, which highlights the enormous versatility of the algorithm to address a number of different tasks (Ardia et al., 2011; Mullen et al., 2011).

\subsection{Brown trout spawning habitat suitability}

\subsubsection{Hydraulic habitat suitability}

As with previous studies that employed a low number of fuzzy sets (Muñoz-Mas et al., 2016b; Fukuda et al., 2013), the TSK fuzzy model achieved moderate accuracy. However, these values were expected after the distribution of the presence and absence data (Fig. 7) and the enforcement of the models' parsimony by selecting a low number of fuzzy sets. Regarding the foregoing, and considering the similarity between omission and commission errors (Mouton et al., 2010), this should not be considered as a limitation of the study.

Mathematically, the TSK fuzzy model performed similarly to habitat suitability curves (Waters, 1976) combined employing the geometric mean (Muñoz-Mas et al., 2012), but trained simultaneously (i.e., in a multivariate manner) and based on the discriminant capability instead of frequency histograms. As a consequence, this approach preserves the interpretability of TSK fuzzy models (Hüllermeier, 2005) - the optimal values can be easily drawn - and it rules out the inconveniences of the forage ratio (Payne and Allen, 2009).

The П-membership functions could be considered a naïve approach compared to B-spline membership functions, which present greater flexibility (Zhang and Knoll, 1998). However, although this approach was envisaged almost 20 years ago, its use is restricted to a small number of studies, thus scientists advocated the piecewise linear versions of the $\Pi$ membership functions (i.e., triangular and trapezoidal membership functions), which present a number of advantages - like П-membership functions - and require fewer 
parameters to be optimised (Barua et al., 2014). Furthermore, П-membership functions are a good fit for the ruling ecological gradient theory, which states that species' responses to environmental variables are likely to be monotone, or unimodal but not necessarily linear or symmetrical (Austin, 2007). Therefore, we considered this type of membership function an optimal choice to further model the habitat suitability with fuzzy rule-based systems.

From the ecological viewpoint, the optimal values for depth, velocity and substrate did not differ substantially from those reported in dedicated reviews or obtained in empirical studies. Louhi et al. (2008), who performed a review of 17 papers, concluded that the optimal velocity and depth were respectively within the range between $0.20-0.55 \mathrm{~m} / \mathrm{s}$ and $0.15-0.45 \mathrm{~m}$, while the optimal substrate type was pebbles $(16-64 \mathrm{~mm})$, which corresponds to gravel in the simplified American Geophysical Union size scale. Moreover, a later study performed in the north of the Iberian Peninsula indicated optimal values that fitted ours even better (Gauthey et al., 2015). In that region brown trout spawned in microhabitats with velocities between $0.1-0.8 \mathrm{~m} / \mathrm{s}$, depth comprised between $0.03-0.77 \mathrm{~m}$, and substrate ranging between 22.3-63.4 mm, which also corresponds to gravel (sensu Muñoz-Mas et al., 2012). Therefore, the acknowledged similarity about optimal water temperature along latitudinal gradients (Ojanguren and Braña, 2003) could be considered extensible to the optimal hydraulics for brown trout spawning. Nonetheless, this conclusion is in agreement with Gauthey et al. (2015), who pointed out the similarity between the brown trout habitat preferences in Iberian (Gauthey et al., 2015) and Alpine rivers (Riedl and Peter, 2013). For the aforementioned, the hydraulic suitability module was considered suitable for the following analyses. 


\subsubsection{Water temperature suitability}

Disentangling the combined effect of hydraulics and water temperature in the wild may potentially imply the systematic survey of a vast area, either with or without redd presence, in order to identify unsuitable temperatures. In this regard, currently there are a number of field and laboratory studies investigating either the effect of hydraulics (e.g., Gauthey et al., 2015) or water temperature (e.g., Réalis-Doyelle et al., 2016). However, to the best of our knowledge, those analysing the combined effect of both elements are restricted to field studies performed over a restricted number of redds and encompassing narrow thermal amplitudes (e.g., Hansen, 1975; Michel et al., 2014). Therefore, based on the acknowledged small variation in embryo thermotolerance along its natural distribution area (Ojanguren and Braña, 2003), we advocated a water temperature suitability module based on scientific literature to complement the data-driven module, which highlights the benefits of employing fuzzy rule-based systems (Mouton et al., 2008).

The optimal value (i.e., $9.09^{\circ} \mathrm{C}$ ) is a good fit for the optimal values indicated in several renowned reviews that performed diverse analyses. Therefore, Armstrong et al. (2003) indicated an optimal range between 1 and $9-10^{\circ} \mathrm{C}$ while Elliott and Elliott (2010) extended this range to $0-13{ }^{\circ} \mathrm{C}$. In other parts of the Jucar River Basin district, the brown trout used for restocking (Alcaraz-Hernández et al., 2016) are successfully incubated at $12{ }^{\circ} \mathrm{C}$. Therefore, taking into account that lower temperatures increase the rate of survival and well-formed fry (Réalis-Doyelle et al., 2016), it was considered a reasonable optima for the populations of the Cabriel River. Thus, in light of current literature, the final habitat suitability model including hydraulics and water temperature rendered plausible preferences to address the subsequent analyses (Elliott and Elliott, 2010; Louhi et al., 2008; Armstrong et al., 2003). 


\subsection{Flow rate changes under the RCPs 4.5 and 8.5 in the short and mid terms}

The predicted changes in the flow regime showed notable uncertainty, (i.e., the changes in the year-round median daily flow rate ranged from $-30 \%$ to $+5 \%$ ). This is consistent with the dispersion described in the literature about the impact of climate change in the Iberian peninsula (Marcos-Garcia and Pulido-Velazquez, 2017; Chirivella Osma et al., 2014; Senatore et al., 2011) and the Mediterranean basin (Girard et al., 2015). With regard to the Cabriel River, the predicted decrease on the median flow between both scenarios and time horizons are smaller than that predicted for an upstream river segment (i.e., 19.70/23.30 vs $27.33 \%$ ) (Muñoz-Mas et al., 2016b). However, the current study site is of higher order while neither the time horizons nor the Global Circulation Models (GCMs) completely coincide, thus an absolute comparison may be inadequate. Nevertheless, unlike studies for Alpine rivers (Junker et al., 2015), none of the approaches indicated increasing running flows, as both studies indicated remarkable reductions.

\subsection{Climate change-induced degradation of the spawning habitat}

Theoretically, the increasing synchrony of high temperature and low flow will potentially lead to synergies resulting in species extirpation (Arismendi et al., 2013). However, although we generally subscribe to such an asseveration, ours and previous results for this particular species and life-cycle stage do not completely match this general pattern (Garbe et al., 2016). Nonetheless, in accordance with the Weighted Usable Area (WUA) vs flow rate and water temperature surface, as well as the Suitable Area (SA) counterpart, the decrease in the magnitude of the running flows can potentially lead to rather positive effects. Leaving aside the water temperature effect, the suitability increases markedly for $Q$ 
$=1.33 \mathrm{~m}^{3} / \mathrm{s}$ and flow rates around this value will be more frequent (Fig. 9). However, the rise in water temperature will not be compensated by the more suitable hydraulics, degrading brown trout spawning habitat between $15.4 \%$ and $48.7 \%$ of the days. Thus, these results, in combination with those obtained in the upper river segment (Muñoz-Mas et al., 2016b), corroborate the gradual shift from physical habitat to temperature as the active environmental limiting factor described for other Iberian rivers (Ayllón et al., 2013).

Iberian brown trout lineages are likely to be better adapted to higher temperatures (Burt et al., 2011). In the past, we observed an extant population, upstream in the same river basin, enduring water temperatures out of what is considered the suitable range (Muñoz-Mas et al., 2016b). However, although local adaptation in brown trout early life-history stages has been observed throughout its natural distribution area (Jensen et al., 2008), the empirical evidence indicated that little room for thermal adaptations exist at the upper temperature limits, either for survival or adequate growth (Ayllón et al., 2013).

Climate change and the shifting flow regime may most probably alter other relevant environmental factors; principally the concentration of dissolved oxygen and sediment transport (Ficklin et al., 2013). The impact on salmonids caused by the excessive loading of river channels with fine sediments is common as a consequence of anthropogenic land use changes (Obruca and Hauer, 2017). However, this is not expected to occur in the Cabriel River Basin because the magnitude of peak flows, which are considered the predominant bedload transport agents (Milan, 2017), is not expected to rise significantly. Therefore, unlike other river segments where winter-flow increases will compromise the stability of the redds (Junker et al., 2015), neither sediment infiltration into gravel interstices nor redd scouring are likely to simultaneously impact brown trout reproduction.

Conversely, rising water temperature is likely to interact with respiration requirements, as the oxygen demand of salmonid embryos increases with temperature (Santiago, 2017), 
which, combined with the expected drop in oxygen concentration (Ficklin et al., 2013), will have dramatic consequences for the viability of the embryos. As a consequence, although the climatological and hydraulic conditions could occasionally be attractive to the species, its reproduction will be rarely, if ever, successful. Trout incubation requires sustained suitable conditions over a period that may vary between $25\left(14{ }^{\circ} \mathrm{C}\right)$ and $105\left(4{ }^{\circ} \mathrm{C}\right)$ days (Santiago, 2017). However, the analyses did not consider the intermittency of the suitable conditions; in particular, that caused by sudden floods or, especially, temperature peaks, which compromise embryo survival to a higher degree. Nonetheless, the latter will be coupled with a drop in oxygen concentration (Ficklin et al., 2013). Therefore, the impact of climate change is likely to be harsher, in terms of percentage, than predicted due to intermittencies in the continued suitable conditions required for the proper development of brown trout embryos. In accordance, we conclude that brown trout spawning is destined to be compelled towards upstream river segments.

The advisability of long-term studies on population dynamics has been emphasised (Rosenfeld, 2017) because fish populations are regulated by birth and mortality processes subject to suites of density-dependent and density-independent factors operating during the lifetime (Lobón-Cerviá, 2009). Nevertheless, this piece of research, complemented by previous studies on summer droughts and adult brown trout (Muñoz-Mas et al., 2016b), indicate that the entire population of the Cabriel River shall suffer the year-round effects of climate change. In accordance, regardless of whether the population is recruitment-limited or habitat-limited (sensu Lobón-Cerviá, 2009), it will probably result in the species extirpation, at least from the downstream river segments. In accordance, this study represents a valuable example of the ultimate impacts of climate change on brown trout spawning success. 


\section{Conclusions}

This study demonstrated that fuzzy rule-based systems combining literature-based and data-driven modules can be used to proficiently predict the impact of different flow and water temperature regimes. The hydraulic data-driven module indicated that the optimal velocity and depth were within the range of $0.20-0.55 \mathrm{~m} / \mathrm{s}$ and $0.15-0.45 \mathrm{~m}$, respectively, and the optimal substrate type was gravel, whereas the literature-based module indicated that the optimal temperature corresponded to $9.09^{\circ} \mathrm{C}$. The values obtained for the hydraulic data-driven module matched well the optimal values described in former reviews whereas the optimal water temperature was slightly inferior to that set to incubate brown trout embryos in local restocking programs. In coherence with former studies and practices, this approach proved proficient to widen the number of environmental factors evaluated and/or the environmental range covered by fuzzy habitat suitability models while $\Pi$-membership functions fitted the ruling ecological gradient theory. This modelling approach combining information from different sources has been used to predict the habitat degradation induced by climate change, although it could easily be used to evaluate different management alternatives in environmental flow assessment studies where environmental and budget constrains exist.

The future scenarios (RCP 4.5 and 8.5 ) predicted a general decrease in the magnitude of running flows, which, with regard exclusively to the hydraulic component, should lead to an increase in the availability of suitable spawning habitats. However, the rise in water temperature will not be compensated by the more suitable hydraulics. In accordance, climate change will degrade brown trout spawning habitat between $15.4 \%$ and $48.7 \%$ of the days for the most pessimistic scenario, which corresponds to the RCP 8.5 and the mid-term horizon (2041-2070). Previous studies focused on future summer droughts revealed that 
adult brown trout will be significantly affected by climate change during that season (MuñozMas et al., 2016b). The negative impact of summer droughts joined to the intermittency in the suitable conditions caused by sudden floods or temperature peaks, foresee that the entire population of the Cabriel River shall suffer the year-round effects of climate change. In accordance, we conclude that brown trout spawning is destined to be extirpated from the lower segments of the Cabriel River. This conclusion should shine a spotlight on the climate change-induced impacts on brown trout populations of the Eastern Iberian Peninsula.

\section{Acknowledgments}

The study has been partially funded by the IMPADAPT project (CGL2013-48424-C2-1-R) with Spanish MINECO (Ministerio de Economía y Competitividad) and FEDER funds and by the Confederación Hidrográfica del Júcar (Spanish Ministry of Agriculture, Food and Environment). The authors thank AEMET and UC for the data provided for this work (dataset Spain02). Finally, we are grateful to the colleagues who worked in the field and in

preliminary data analyses; especially Marcello Minervini (funded by the EU programme of Erasmus Traineeships, at the Dept. of Hydraulic Engineering and Environment, Universitat Politècnica de València).

\section{References}

Adriaenssens, V., De Baets, B., Goethals, P.L.M., De Pauw, N., 2004. Fuzzy rule-based models for decision support in ecosystem management. Sci. Total Environ. 319 (1-3), 1-12. 10.1016/S0048-9697(03)00433-9 
Alcaraz-Hernández, J.D.D., Muñoz-Mas, R., Martínez-Capel, F., Garófano-Gómez, V., Vezza, P., 2016. Generalized additive models to predict adult and young brown trout (Salmo trutta Linnaeus, 1758) densities in Mediterranean rivers. J. Appl. Ichthyol. 32 (1), 217-228. 10.1111/jai.13025

Ardia, D., Boudt, K., Carl, P., Mullen, K.M., Peterson, B.G., 2011. Differential evolution with deoptim. R J. 3 (1), 27-34.

Arismendi, I., Safeeq, M., Johnson, S.L., Dunham, J.B., Haggerty, R., 2013. Increasing synchrony of high temperature and low flow in western North American streams: Double trouble for coldwater biota? Hydrobiologia 712 (1). 10.1007/s10750-012-1327-2

Arlot, S., Celisse, A., 2010. A survey of cross-validation procedures for model selection. Stat. Surv. 4, 40-79. 10.1214/09-SS054

Armstrong, J.D., Kemp, P.S., Kennedy, G.J.A., Ladle, M., Milner, N.J., 2003. Habitat requirements of Atlantic salmon and brown trout in rivers and streams. Fish. Res. 62 (2), 143-170. http://dx.doi.org/10.1016/S0165-7836(02)00160-1

Austin, M., 2007. Species distribution models and ecological theory: A critical assessment and some possible new approaches. Ecol. Modell. 200 (1-2), 1-19. 10.1016/j.ecolmodel.2006.07.005

Ayllón, D., Nicola, G.G., Elvira, B., Parra, I., Almodóvar, A., 2013. Thermal Carrying Capacity for a Thermally-Sensitive Species at the Warmest Edge of Its Range. PLoS One 8 (11), e81354. 10.1371/journal.pone.0081354

Barker, G.A., Smith, S.N., Bromage, N.R., 1989. The bacterial flora of rainbow trout, Salmo gairdneri Richardson, and brown trout, Salmo trutta L., eggs and its relationship to developmental success. J. Fish Dis. 12 (4). 10.1111/j.1365-2761.1989.tb00317.x

Barua, A., Mudunuri, L.S., Kosheleva, O., 2014. Why trapezoidal and triangular 
membership functions work so well: Towards a theoretical explanation. J. Uncertain Syst. 8 (3), 164-168.

Bergström, S., 1976. Development and application of a conceptual runoff model for Scandinavian catchments. Lund (Sweden).

Bi, J., Bennett, K.P., 2003. A geometric approach to support vector regression. Neurocomputing 55 (1), 79-108. 10.1016/S0925-2312(03)00380-1

Boavida, I., Dias, V., Ferreira, M.T., Santos, J.M., 2014. Univariate functions versus fuzzy logic: Implications for fish habitat modeling. Ecol. Eng. 71, 533-538. 10.1016/j.ecoleng.2014.07.073

Bossard, M., Feranec, J., Otahel, J., 2000. CORINE land cover technical guide - Addendum 2000. Copenhagen (Denmark).

Bovee, K.D., 1982. A Guide to Stream Habitat Analysis Using the Instream Flow Incremental Methodology. Instream Flow Information, U.S. Fish Wildl. Serv. Fort Collins, Color. (12), 248.

Bovee, K.D., 1978. Probability of use criteria for the family Salmonidae. Instream Flow Information Paper No. 4. FWS/OBS-78/07. Washington DC, (USA).

Bovee, K.D., Lamb, B.L., Bartholow, J.M., Stalnaker, C.B., Taylor, J., Henriksen, J., 1998. Stream habitat analysis using the instream flow incremental methodology. Fort Collins, CO (USA).

Burt, J.M., Hinch, S.G., Patterson, D.A., 2011. The importance of parentage in assessing temperature effects on fish early life history: A review of the experimental literature. Rev. Fish Biol. Fish. 21 (3). 10.1007/s11160-010-9179-1

Capra, H., Breil, P., Souchon, Y., 1995. A new tool to interpret magnitude and duration of 
fish habitat variations. Regul. Rivers Res. Manag. 10 (2-4), 281-289. 10.1002/rrr.3450100221

Caputo, B., Sim, K., Furesjo, F., Smola, A., 2002. Appearance-based object recognition using SVMs: which kernel should I use?, in: Proc of NIPS Workshop on Statistical Methods for Computational Experiments in Visual Processing and Computer Vision. Whistler, BC (Canada).

Castro, J.L., 1995. Fuzzy logic controllers are universal approximators. IEEE Trans. Syst. Man Cybern. 25 (4), 629-635. 10.1109/21.370193

Chirivella Osma, V., Capilla Romá, J.E.E., Pérez Martín, M.A.A., Osma, V.C., Romá, J.E.C., Martín, M.A.P., 2014. Modelling regional impacts of climate change on water resources: the Júcar basin, Spain. Hydrol. Sci. J. 60 (1), 30-49. $10.1080 / 02626667.2013 .866711$

Christensen, O.B., Gutowski, W.J., Nikulin, G., Legutke, S., 2014. CORDEX Archive Design.

Clavero, M., Ninyerola, M., Hermoso, V., Filipe, A.F., Pla, M., Villero, D., et al., 2017. Historical citizen science to understand and predict climate-driven trout decline. Proc. R. Soc. London B Biol. Sci. 284 (1846). 10.1098/rspb.2016.1979

Comte, L., Buisson, L., Daufresne, M., Grenouillet, G., 2013. Climate-induced changes in the distribution of freshwater fish: observed and predicted trends. Freshw. Biol. 58 (4), 625-639. 10.1111/fwb.12081

Cornwell, W.K., Schwilk, D.W., Ackerly, D.D., 2006. A trait-based test for habitat filtering: Convex hull volume. Ecology 87 (6), 1465-1471. 10.1890/00129658(2006)87[1465:ATTFHF]2.0.CO;2

Costa, R.M.S., Martínez-Capel, F., Muñoz-Mas, R., Alcaraz-Hernández, J.D., Garófano- 
Gómez, V., 2012. Habitat suitability modelling at mesohabitat scale and effects of dam operation on the endangered Júcar nase, Parachondrostoma arrigonis (River Cabriel, Spain). River Res. Appl. 28 (6), 740-752. 10.1002/rra.1598

Elliott, J.M., 2000. Pools as refugia for brown trout during two summer droughts: trout responses to thermal and oxygen stress. J. Fish Biol. 56 (4), 938-948. 10.1111/j.10958649.2000.tb00883.x

Elliott, J.M., 1984. Numerical changes and population regulation in young migratory trout Salmo trutta in a Lake District stream, 1966-83. J. Anim. Ecol. 53 (1).

Elliott, J.M., Elliott, J.A., 2010. Temperature requirements of Atlantic salmon Salmo salar, brown trout Salmo trutta and Arctic charr Salvelinus alpinus: Predicting the effects of climate change. J. Fish Biol. 77 (8), 1793-1817. 10.1111/j.1095-8649.2010.02762.x

Embody, G.C., 1934. Relation of Temperature to the Incubation Periods of Eggs of Four Species of Trout. Trans. Am. Fish. Soc. 64 (1), 281-292. 10.1577/15488659(1934)64[281:ROTTTI]2.0.CO;2

Fausch, K.D., Northcote, T.G., 1992. Large woody debris and salmonid habitat in a small coastal British Columbia stream. Can. J. Fish. Aquat. Sci. 49 (4), 682-693. 10.1139/f92-077

Ficklin, D.L., Stewart, I.T., Maurer, E.P., 2013. Effects of climate change on stream temperature, dissolved oxygen, and sediment concentration in the Sierra Nevada in California. Water Resour. Res. 49 (5). 10.1002/wrcr.20248

Fridedman, J.H., 1991. Multivariate adaptive regression splines (with discussion). Ann. Stat. 19 (1), 79-141.

Fukuda, S., 2013. Effects of data prevalence on species distribution modelling using a genetic takagi-sugeno fuzzy system, in: IEEE International Workshop on Genetic and 
Evolutionary Fuzzy Systems (GEFS). Singapore, pp. 21-27.

Fukuda, S., De Baets, B., Waegeman, W., Verwaeren, J., Mouton, A.M., 2013. Habitat prediction and knowledge extraction for spawning European grayling (Thymallus thymallus L.) using a broad range of species distribution models. Environ. Model. Softw. 47, 1-6. 10.1016/j.envsoft.2013.04.005

Garbe, J., Beevers, L., Pender, G., 2016. The interaction of low flow conditions and spawning brown trout (Salmo trutta) habitat availability. Ecol. Eng. 88, 53-63. 10.1016/j.ecoleng.2015.12.011

Gauthey, Z., Lang, M., Elosegi, A., Tentelier, C., Rives, J., Labonne, J., 2015. Brown trout spawning habitat selection and its effects on egg survival. Ecol. Freshw. Fish 26 (1), 133-140. 10.1111/eff.12262

Girard, C., Pulido-Velazquez, M., Rinaudo, J.-D., Pagé, C., Caballero, Y., 2015. Integrating top-down and bottom-up approaches to design global change adaptation at the river basin scale. Glob. Environ. Chang. 34. 10.1016/j.gloenvcha.2015.07.002

Gudmundsson, L., Bremnes, J.B., Haugen, J.E., Engen-Skaugen, T., 2012. Technical Note: Downscaling RCM precipitation to the station scale using statistical transformations - A comparison of methods. Hydrol. Earth Syst. Sci. 16 (9), 3383-3390.

Hampe, A., Petit, R.J., 2005. Conserving biodiversity under climate change: the rear edge matters. Ecol. Lett. 8 (5), 461-7. 10.1111/j.1461-0248.2005.00739.x

Hansen, E.A., 1975. Some Effects of Groundwater on Brown Trout Redds. Trans. Am. Fish. Soc. 104 (1), 100-110. 10.1577/1548-8659(1975)104<100:SEOGOB>2.0.CO;2

Hastie, T.J., Tibshirani, R.J., 1990. Generalized Additive Models, Monographs on Statistics \& Applied Probability. London, (UK). 
Hauer, C., Unfer, G., Holzmann, H., Schmutz, S., Habersack, H., 2013. The impact of discharge change on physical instream habitats and its response to river morphology. Clim. Change 116 (3-4), 827-850. http://dx.doi.org/10.1007/s10584-012-0507-4

Hüllermeier, E., 2005. Fuzzy methods in machine learning and data mining: Status and prospects. Fuzzy Sets Syst. 156 (3), 387-406. 10.1016/j.fss.2005.05.036

Humpesch, U.H., 1985. Inter- and intra-specific variation in hatching success and embryonic development of five species of salmonids on Thymallus thymallus. Arch. für Hydrobiol. 104 (1), 129-144.

Hutchinson, G.E., 1957. Population studies - animal ecology and demography - concluding remarks, in: Cold Spring Harbor Symposia on Quantitative Biology. pp. 415-427.

IPCC, 2014. Climate Change 2014: Summary for Policymakers. In: Climate Change 2014: Impacts, Adaptation, and Vulnerability. Part A: Global and Sectoral Aspects. Contribution of Working Group II to the Fifth Assessment Report of the Intergovernmental Panel on Climate . Cambridge, United Kingdom and New York, NY (USA).

Isaak, D.J., Rieman, B.E., 2013. Stream isotherm shifts from climate change and implications for distributions of ectothermic organisms. Glob. Chang. Biol. 19 (3), 742751. $10.1111 / g c b .12073$

Jang, J.-S.R., 1993. ANFIS: Adaptive-Network-Based Fuzzy Inference System. IEEE Trans. Syst. Man Cybern. 23 (3). 10.1109/21.256541

Jensen, L.F., Hansen, M.M., Pertoldi, C., Holdensgaard, G., Mensberg, K.-L.D., Loeschcke, V., 2008. Local adaptation in brown trout early life-history traits: Implications for climate change adaptability. Proc. R. Soc. B Biol. Sci. 275 (1653). 10.1098/rspb.2008.0870

Jowett, I.G., Duncan, M.J., 2012. Effectiveness of 1D and 2D hydraulic models for instream 
habitat analysis in a braided river. Ecol. Eng. 48, 92-100. 10.1016/j.ecoleng.2011.06.036

Jungwirth, M., Winkler, H., 1984. The temperature dependence of embryonic development of grayling (Thymallus thymallus), Danube salmon (Hucho hucho), Arctic char (Salvelinus alpinus) and brown trout (Salmo trutta fario). Aquaculture 38 (4), 315-327. 10.1016/0044-8486(84)90336-3

Junker, J., Heimann, F.U.M., Hauer, C., Turowski, J.M., Rickenmann, D., Zappa, M., et al., 2015. Assessing the impact of climate change on brown trout (Salmo trutta fario) recruitment. Hydrobiologia 751 (1), 1-21. 10.1007/s10750-014-2073-4

Klemetsen, A., Amundsen, P.A., Dempson, J.B., Jonsson, B., Jonsson, N., O’Connell, M.F., et al., 2003. Atlantic salmon Salmo salar L., brown trout Salmo trutta L. and Arctic charr Salvelinus alpinus (L.): A review of aspects of their life histories. Ecol. Freshw. Fish 12 (1), 1-59. 10.1034/j.1600-0633.2003.00010.x

Kovach, R.P., Muhlfeld, C.C., Al-Chokhachy, R., Dunham, J.B., Letcher, B.H., Kershner, J.L., 2016. Impacts of climatic variation on trout: a global synthesis and path forward. Rev. Fish Biol. Fish. 26 (2). 10.1007/s11160-015-9414-x

Kruschke, J.K., 2013. Bayesian estimation supersedes the T test. J. Exp. Psychol. Gen. 142 (2), 573-603. 10.1037/a0029177

Kuhn, M., Weston, S., Keefer, C., Coulter, N., 2014. Cubist: Rule- and Instance-Based Regression Modeling - C code for Cubist by Ross Quinlan -.

Laanaya, F., St-Hilaire, A., Gloaguen, E., 2017. Water temperature modelling: comparison between the generalized additive model, logistic, residuals regression and linear regression models. Hydrol. Sci. J. 62 (7). 10.1080/02626667.2016.1246799

Lahnsteiner, F., 2012. Thermotolerance of brown trout, Salmo trutta, gametes and embryos 
to increased water temperatures. J. Appl. Ichthyol. 28 (5). 10.1111/j.14390426.2012.01934.x

Lassalle, G., Rochard, E., 2009. Impact of twenty-first century climate change on diadromous fish spread over Europe, North Africa and the Middle East. Glob. Chang. Biol. 15 (5), 1072-1089. 10.1111/j.1365-2486.2008.01794.x

Li, H., Sheffield, J., Wood, E.F., 2010. Bias correction of monthly precipitation and temperature fields from Intergovernmental Panel on Climate Change AR4 models using equidistant quantile matching. J. Geophys. Res. 115 (D10), D10101. 10.1029/2009JD012882

Li, R., Chen, Q., Tonina, D., Cai, D., 2015. Effects of upstream reservoir regulation on the hydrological regime and fish habitats of the Lijiang River, China. Ecol. Hydrol. responses to Chang. Environ. Cond. China's river basins 76 (0), 75-83. 10.1016/j.ecoleng.2014.04.021

Lin, Y.-P., Lin, W.-C., Wu, W.-Y., 2015. Uncertainty in various habitat suitability models and its impact on habitat suitability estimates for fish. Water 7 (8), 4088-4107. $10.3390 / w 7084088$

Lobón-Cerviá, J., 2009. Recruitment as a driver of production dynamics in stream-resident brown trout (Salmo trutta). Freshw. Biol. 54 (8), 1692-1704. 10.1111/j.13652427.2009.02218.x

Louhi, P., Mäki-Petäys, A., Erkinaro, J., 2008. Spawning habitat of Atlantic salmon and brown trout: General criteria and intragravel factors. River Res. Appl. 24 (3), 330-339.

Mamdani, E.H., 1974. Application of fuzzy algorithms for control of simple dynamic plant. Proc. Inst. Electr. Eng. 121 (12), 1585-1588. 10.1049/piee.1974.0328

Marcos-Garcia, P., Pulido-Velazquez, M., 2017. Cambio climático y planificación 
hidrológica: ¿es adecuado asumir un porcentaje único de reducción de aportaciones para toda la demarcación? Ing. del agua Vol. 21, N. 10.4995/ia.2017.6361

May, R., Dandy, G., Maier, H., 2011. Review of input variable selection methods for Artificial Neural Networks, in: Suzuki, K. (Ed.), Artificial Neural Networks Methodological Advances and Biomedical Applications. p. 362.

Meybeck, M., 2004. The global change of continental aquatic systems: Dominant impacts of human activities. Water Sci. Technol. 49 (7), 73-83.

Meyer, F.P., 1991. Aquaculture disease and health management. J. Anim. Sci. 69 (10).

Michel, C., Schindler Wildhaber, Y., Epting, J., Thorpe, K.L., Huggenberger, P., Alewell, C., et al., 2014. Artificial steps mitigate the effect of fine sediment on the survival of brown trout embryos in a heavily modified river. Freshw. Biol. 59 (3). 10.1111/fwb.12284

Milan, D., 2017. Controls on spatial and temporal variations in sand delivery to salmonid spawning riffles. Hydrol. Process. 10.1002/hyp.11172

Milborrow, S., 2016. earth: Multivariate Adaptive Regression Splines. Derived from mda:mars by Trevor Hastie and Rob Tibshirani. Uses Alan Miller's Fortran utilities with Thomas Lumley's leaps wrapper.

Milborrow, S., 2014. Notes on the earth package.

Milhous, R.T., Bartholow, J.M., Updike, M.A., Moos, A.R., 1990. Reference manual for generation and analysis of Habitat Time Series - Version II, Instream Flow Information Paper. Fort Collins, CO (USA).

Mouton, A.M., Alcaraz-Hernández, J.D., De Baets, B., Goethals, P.L.M., Martínez-Capel, F., 2011. Data-driven fuzzy habitat suitability models for brown trout in Spanish Mediterranean rivers. Environ. Model. Softw. 26 (5), 615-622. 
10.1016/j.envsoft.2010.12.001

Mouton, A.M., De Baets, B., Goethals, P.L.M., 2010. Ecological relevance of performance criteria for species distribution models. Ecol. Modell. 221 (16), 1995-2002. 10.1016/j.ecolmodel.2010.04.017

Moyle, P.B., 2002. Inland Fishes of California. Berkeley, CA (USA).

Mullen, K.M., Ardia, D., Gil, D.L., Windover, D., Cline, J., 2011. DEoptim: An R package for global optimization by differential evolution. J. Stat. Softw. 40 (6), 1-26. 10.18637/jss.v040.i06

Muñoz-Mas, R., Fukuda, S., Vezza, P., Martínez-Capel, F., 2016a. Comparing four methods for decision-tree induction: A case study on the invasive Iberian gudgeon (Gobio lozanoi; Doadrio and Madeira, 2004). Ecol. Inform. 34, 22-34. 10.1016/j.ecoinf.2016.04.011

Muñoz-Mas, R., Lopez-Nicolas, A., Martínez-Capel, F., Pulido-Velazquez, M., 2016b. Shifts in the suitable habitat available for brown trout (Salmo trutta L.) under short-term climate change scenarios. Sci. Total Environ. 544, 686-700. 10.1016/j.scitotenv.2015.11.147

Muñoz-Mas, R., Martínez-Capel, F., Alcaraz-Hernández, J.D., Mouton, A.M., 2016c. On species distribution modelling, spatial scales and environmental flow assessment with Multi-Layer Perceptron Ensembles: A case study on the redfin barbel (Barbus haasi; Mertens, 1925). Limnol. - Ecol. Manag. Inl. Waters. 10.1016/j.limno.2016.09.004

Muñoz-Mas, R., Martínez-Capel, F., Schneider, M., Mouton, A.M., 2012. Assessment of brown trout habitat suitability in the Jucar River Basin (Spain): Comparison of datadriven approaches with fuzzy-logic models and univariate suitability curves. Sci. Total Environ. 440, 123-131. 10.1016/j.scitotenv.2012.07.074 
Muñoz-Mas, R., Papadaki, C., Martínez-Capel, F., Zogaris, S., Ntoanidis, L., Dimitriou, E., 2016d. Generalized additive and fuzzy models in environmental flow assessment: A comparison employing the West Balkan trout (Salmo farioides; Karaman, 1938). Ecol. Eng. 91, 365-377. 10.1016/j.ecoleng.2016.03.009

Muñoz-Mas, R., Vezza, P., Alcaraz-Hernández, J.D., Martínez-Capel, F., 2016e. Risk of invasion predicted with support vector machines: A case study on northern pike (Esox Lucius, L.) and bleak (Alburnus alburnus, L.). Ecol. Modell. 342, 123-134. 10.1016/j.ecolmodel.2016.10.006

NASA, 2017. 2016 warmest year on record globally, NASA and NOAA data show: Third record-breaking year in a row for average surface temperatures [WWW Document]. ScienceDaily.

Noack, M., Ortlepp, J., Wieprecht, S., 2017. An approach to simulate interstitial habitat conditions during the incubation phase of gravel-spawning fish. River Res. Appl. 33 (2). 10.1002/rra.3012

Norris, T., 1868. American fish-culture, embracing all the details of artificial breeding and rearing of trout; the culture of salmon, shad, and other fishes. Philadelphia, PA (USA).

Obruca, W., Hauer, C., 2017. Physical laboratory analyses of intergravel flow through brown trout redds (Salmo trutta fario) in response to coarse sand infiltration. Earth Surf Process. Landforms 42 (4). 10.1002/esp.4009

Ojanguren, A.F., Braña, F., 2003. Thermal dependence of embryonic growth and development in brown trout. J. Fish Biol. 62 (3), 580-590. 10.1046/j.10958649.2003.00049.x

Parasiewicz, P., 2008. Habitat time series analysis to define flow augmentation strategy for the Quinebaug River, Connecticut and Massachusetts, USA. River Res. Appl. 24 (4), 
439-452. 10.1002/rra.1066

Payne, T.R., 2003. The concept of Weighted Usable Area as relative suitability index, in: IFIM Users Workshop. Fort Collins, CO (USA).

Payne, T.R., Allen, M.A., 2009. Application of the use-to-availability electivity ratio for developing habitat suitability criteria in PHABSIM instream flow studies, in: Proceedings of the 7th International Symposium on Ecohydraulics. Concepción (Chile), p. .

Perkins, D.M., Reiss, J., Yvon-Durocher, G., Woodward, G., 2010. Global change and food webs in running waters. Hydrobiologia 657 (1), 181-198. 10.1007/s10750-009-0080-7

Person, E., Bieri, M., Peter, A., Schleiss, A.J., 2014. Mitigation measures for fish habitat improvement in Alpine rivers affected by hydropower operations. Ecohydrology 7 (2), 580-599. http://dx.doi.org/10.1002/eco.1380

Piccolroaz, S., Calamita, E., Majone, B., Gallice, A., Siviglia, A., Toffolon, M., 2016. Prediction of river water temperature: a comparison between a new family of hybrid models and statistical approaches. Hydrol. Process. 30 (21). 10.1002/hyp.10913

Poff, N.L., Allan, J.D., Bain, M.B., Karr, J.R., Prestegaard, K.L., Richter, B.D., et al., 1997. The natural flow regime: a paradigm for river conservation and restoration. Bioscience 47 (11), 769-784. 10.2307/1313099

Quinlan, J.R., 1992. Learning with continuous classes, in: The 5th Australian Joint Conference on Al. Sydney (Australia), pp. 343-348.

Rabin-Havt, A., 2016. Lies, Incorporated: The World of Post-Truth Politics.

Radtke, G., 2013. Effects of substrate composition and water temperature on the emergence success of lacustrine brown trout Salmo trutta m. lacustris L. fry from 
natural redds. Folia Zool. 62 (4).

Raleigh, R.F., Zuckerman, L.D., Nelson, P.C., 1986. Habitat suitability index models and instream flow suitability curves: brown trout, revised. Washington DC, (USA).

Ratuva, S., 2017. Anxiety and Diminished Hope: The Potential Impact of Trump's Presidency on Security in the Pacific Islands Region. Round Table 106 (2), 165-173. $10.1080 / 00358533.2017 .1296711$

Réalis-Doyelle, E., Pasquet, A., De Charleroy, D., Fontaine, P., Teletchea, F., 2016. Strong Effects of Temperature on the Early Life Stages of a Cold Stenothermal Fish Species, Brown Trout (Salmo trutta L.). PLoS One 11 (5), e0155487.

Ren, Y., Zhang, L., Suganthan, P.N., 2016. Ensemble Classification and RegressionRecent Developments, Applications and Future Directions. IEEE Comput. Intell. Mag. $11(1), 41-53.10 .1109 / \mathrm{MCl} .2015 .2471235$

Riahi, K., Grübler, A., Nakicenovic, N., 2007. Scenarios of long-term socio-economic and environmental development under climate stabilization. Technol. Forecast. Soc. Change 74 (7), 887-935. 10.1016/j.techfore.2006.05.026

Riedl, C., Peter, A., 2013. Timing of brown trout spawning in Alpine rivers with special consideration of egg burial depth. Ecol. Freshw. Fish 22 (3), 384-397. 10.1111/eff.12033

Rosenfeld, J.S., 2017. Developing flow-ecology relationships: Implications of nonlinear biological responses for water management. Freshw. Biol. 62 (8), 1305-1324. $10.1111 / f w b .12948$

Salmoral, G., Willaarts, B.A.A., Troch, P.A.A., Garrido, A., 2015. Drivers influencing streamflow changes in the Upper Turia basin, Spain. Sci. Total Environ. 503-504, 258268. 10.1016/j.scitotenv.2014.07.041 
Sánchez-Hernández, J., Nunn, A.D., 2016. Environmental changes in a Mediterranean river: implications for the fish assemblage. Ecohydrology 9 (8), 1439-1451. 10.1002/eco.1737

Santiago, J.M., 2017. Thermal ecology of brown trout and the climate change challenge, in: Richardson, B. (Ed.), Tilapia and Trout: Harvesting, Prevalence and Benefits. New York City, NY (USA), pp. 79-119.

Santiago, J.M., García de Jalón, D., Alonso, C., Solana, J., Ribalaygua, J., Pórtoles, J., et al., 2015. Brown trout thermal niche and climate change: Expected changes in the distribution of cold-water fish in central Spain. Ecohydrology 9 (3), 514-528. 10.1002/eco.1653

Santiago, J.M., Muñoz-Mas, R., Solana, J., de Jalón, D., Alonso, C., Martínez-Capel, F., et al., 2017. Waning habitats due to climate change: effects of streamflow and temperature changes at the rear edge of the distribution of a cold-water fish. Hydrol. Earth Syst. Sci. Discuss. 2017, 1-37. 10.5194/hess-2016-606

Santos, J.M., Godinho, F., Ferreira, M.T., Cortes, R., 2004. The organisation of fish assemblages in the regulated Lima basin, Northern Portugal. Limnologica 34 (3), 224235.

Seibert, J., Vis, M.J.P., 2012. Teaching hydrological modeling with a user-friendly catchment-runoff-model software package. Hydrol. Earth Syst. Sci. 16 (9). 10.5194/hess-16-3315-2012

Senatore, A., Mendicino, G., Smiatek, G., Kunstmann, H., 2011. Regional climate change projections and hydrological impact analysis for a Mediterranean basin in Southern Italy. J. Hydrol. 399 (1-2). 10.1016/j.jhydrol.2010.12.035

Steffler, P., Blackburn, J., 2002. River2D 0.90. 
Storn, R., Price, K., 1997. Differential Evolution - A Simple and Efficient Heuristic for global Optimization over Continuous Spaces. J. Glob. Optim. 11 (4), 341-359. 10.1023/A:1008202821328

Strahler, A.N., 1952. Hypsometric (area-altitude) analysis of erosional topography. Geol. Soc. Am. Bull. 63, 25-1117.

Takagi, T., Sugeno, M., 1985. Fuzzy identification of systems and its applications to modeling and control. IEEE Trans. Syst. Man Cybern. 15 (1), 116-132. 10.1109/TSMC.1985.6313399

Thomson, A.M., Calvin, K. V, Smith, S.J., Kyle, G.P., Volke, A., Patel, P., et al., 2011. RCP4.5: A pathway for stabilization of radiative forcing by 2100 . Clim. Change 109 (1), 77-94.

Tisseuil, C., Vrac, M., Grenouillet, G., Wade, A.J., Gevrey, M., Oberdorff, T., et al., 2012. Strengthening the link between climate, hydrological and species distribution modeling to assess the impacts of climate change on freshwater biodiversity. Sci. Total Environ. 424, 193-201. 10.1016/j.scitotenv.2012.02.035

Townsend, C.R., Hildrew, A.G., 1994. Species traits in relation to a habitat templet for river systems. Freshw. Biol. 31 (3), 265-275. 10.1111/j.1365-2427.1994.tb01740.x

Turner, M., Stewardson, M., 2014. Hydrologic indicators of hydraulic conditions that drive flow-biota relationships. Hydrol. Sci. J. 59 (3-4), 659-672. $10.1080 / 02626667.2014 .896997$

Van Vliet, M.T.H., Franssen, W.H.P., Yearsley, J.R., Ludwig, F., Haddeland, I., Lettenmaier, D.P., et al., 2013. Global river discharge and water temperature under climate change. Glob. Environ. Chang. 23 (2), 450-464. 10.1016/j.gloenvcha.2012.11.002

Vapnik, V., Golowich, S.E., Smola, A., 1997. Support vector method for function 
approximation, regression estimation, and signal processing, in: Mozer, M., Jordan, M., Petsche, T. (Eds.), Advances in Neural Information Processing Systems 9. Denver, CO (USA), pp. 281-287.

Veeramachaneni, S., Williams, K., 2014. LinearizedSVR: Linearized Support Vector Regression.

Vezza, P., Muñoz-Mas, R., Martinez-Capel, F., Mouton, A., Martínez-Capel, F., Mouton, A., 2015. Random forests to evaluate biotic interactions in fish distribution models. Environ. Model. Softw. 67, 173-183. 10.1016/j.envsoft.2015.01.005

Viganò, G., Confortola, G., Fornaroli, R., Cabrini, R., Canobbio, S., Mezzanotte, V., et al., 2015. Effects of future climate change on a river habitat in an Italian Alpine catchment. J. Hydrol. Eng. 21 (2), 1-14. 10.1061/(ASCE)HE.1943-5584.0001293

Warrner, S.S., Fischer, R.U., Holtrop, A.M., Hinz Jr., L.C., Novak, J.M., 2010. Evaluating the Illinois stream valley segment model as an effective management tool. Environ. Manage. 46 (5). 10.1007/s00267-010-9551-x

Waters, B.F., 1976. A Methodology for Evaluating the Effects of Different Streamflows on Salmonid Habitat, in: Proceedings of the Symposium and Specialty Conference on Instream Flow Needs. Bethesda, MD (USA), p. 13.

Wenger, S.J., Isaak, D.J., Luce, C.H., Neville, H.M., Fausch, K.D., Dunham, J.B., et al., 2011. Flow regime, temperature, and biotic interactions drive differential declines of trout species under climate change. Proc. Natl. Acad. Sci. U. S. A. 108 (34), 1417514180. 10.1073/pnas.1103097108

Wes Stonecypher, R., Hubert, W.A., Gern, W.A., 1994. Effect of reduced incubation temperatures on survival of trout embryos. Progress. Fish-Culturist 56 (3). 10.1577/1548-8640(1994)056\&lt;0180:EORITO\&gt;2.3.CO;2 
Witzel, L.D., Maccrimmon, H.R., 1983. Redd-Site Selection by Brook Trout and Brown Trout in Southwestern Ontario Streams. Trans. Am. Fish. Soc. 112 (6), 760-771. 10.1577/1548-8659(1983)112<760:RSBBTA>2.0.CO;2

Zadeh, L.A., 1965. Fuzzy sets. Inf. Control 8 (3), 338-353. 10.1016/S0019-9958(65)90241$X$

Zhang, J., Knoll, A., 1998. Constructing fuzzy controllers with B-spline models - Principles and applications. Int. J. Intell. Syst. 13 (2-3). 